\title{
(Crossark The cursed duet today: Tuberculosis and HIV-coinfection
}

\author{
Simon Tiberi ${ }^{1,11}$, Anna Cristina C. Carvalho ${ }^{2,11}$, Giorgia Sulis ${ }^{3,11}$, Devan Vaghela ${ }^{4,11}$, Adrian Rendon ${ }^{5}$, \\ Fernanda C. de Q. Mello ${ }^{6}$, Ananna Rahman ${ }^{7}$, Nashaba Matin ${ }^{8}$, Ali Zumla ${ }^{9}$, Emanuele Pontali ${ }^{10}$
}

1. Barts health NHS trust, Royal London hospital, division of infection, 80, Newark street, E1 2ES London, United Kingdom

2. Oswaldo Cruz institute (IOC), laboratory of innovations in therapies, education and bioproducts, (LITEB), Fiocruz, Rio de Janeiro, Brazil

3. University of Brescia, university department of infectious and tropical diseases, World health organization collaborating centre for TB/HIV co-infection and TB elimination, Brescia, Italy

4. Barts Health NHS Trust, Royal London hospital, department of respiratory medicine, 80, Newark street, E1 2ES London, United Kingdom

5. Hospital universitario de Monterrey, centro de investigación, prevención y tratamiento de infecciones respiratorias, Monterrey, Nuevo León UANL, Mexico

In this issue

Editorial

World Tuberculosis Day 2017: strengthening the fight against tuberculosis. I. Solovic (Slovakia) et al.

Breaking the barriers: Migrants and tuberculosis. G. Sotgiu (Italy) et al.

Tuberculosis elimination and the challenge of latent tuberculosis.

A. Matteelli (Italy) et al.

The cursed duet today: Tuberculosis and HIVcoinfection.

S. Tiberi (UK) et al.

The challenge of the new tuberculosis drugs. S. Tiberi (UK) et al.

Agents of change: The role of healthcare workers in the prevention of nosocomial and occupational tuberculosis.

R.R. Nathavitharana (USA) et al.
6. Federal university of Rio de Janeiro, instituto de Doenças do Tórax (IDT)/ Clementino Fraga Filho hospital (CFFH), rua Professor Rodolpho Paulo Rocco, $n^{\circ}$ 255 - $1^{\circ}$ Andar - Cidade Universitária - Ilha do Fundão, 21941-913, Rio De Janeiro, Brazil

7. Papworth hospital NHS foundation trust, department of respiratory medicine, Papworth Everard, Cambridge, United Kingdom

8. Barts Health NHS Trust, Royal London hospital, HIV medicine, infection and immunity, London, United Kingdom

9. UCL hospitals NHS Foundation Trust, university college London, NIHR biomedical research centre, division of infection and immunity, London, United Kingdom

10. Galliera hospital, department of infectious diseases, Genoa, Italy

\section{Correspondence:}

Simon Tiberi, Barts health NHS trust, Royal London hospital, division of infection, 80, Newark street, London E1 2ES, United Kingdom.

simon.tiberi@bartshealth.nhs.uk

\section{Summary}

The tuberculosis (TB) and HIV syndemic continues to rage and are a major public health concern worldwide. This deadly association raises complexity and represent a significant barrier towards TB elimination. TB continues to be the leading cause of death amongst HIV-infected people. This paper reports the challenges that lay ahead and outlines some of the current and future strategies that may be able to address this co-epidemic efficiently. Improved diagnostics, cheaper and more effective drugs, shorter treatment regimens for both drug-sensitive and drug-resistant TB are discussed. Also, special topics on drug interactions, TB-IRIS and TB relapse are also described. Notwithstanding the defeats and meagre investments, diagnosis and management of the two diseases have seen significant and unexpected improvements of late. On the HIV side, expansion

11 Contributed equally. 
of ART coverage, development of new updated guidelines aimed at the universal treatment of those infected, and the increasing availability of newer, more efficacious and less toxic drugs are an essential element to controlling the two epidemics. On the TB side, diagnosis of MDR-TB is becoming easier and faster thanks to the new PCR-based technologies, new anti-TB drugs active against both sensitive and resistant strains (i.e. bedaquiline and delamanid) have been developed and a few more are in the pipeline, new regimens (cheaper, shorter and/or more effective) have been introduced (such as the "Bangladesh regimen") or are being tested for MDR-TB and drugsensitive-TB. However, still more resources will be required to implement an integrated approach, install new diagnostic tests, and develop simpler and shorter treatment regimens.

\section{Introduction}

The World health organisation (WHO) reported major advances in the treatment of tuberculosis (TB) disease, with a $47 \%$ reduction in mortality between 1990 and 2015. The incidence of TB had fallen by $1.4 \%$ every year since 2000 , but due to better reporting had risen to an incidence of 10.4 million cases in 2015, $11 \%$ of whom had human immunodeficiency virus (HIV) infection. Following the geographical distribution of the two epidemics, TB/HIV cases are mainly concentrated in Sub-Saharan Africa and former-Soviet Union countries (table I) [1].

TB is the most prevalent opportunistic disease among people living with HIV (PLHIV), and the most common presenting illness in newly HIV diagnosed patients. Approximately 400,000 HIVinfected persons died of TB in 2015 [1], which accounted for nearly one-third of all mortality in this high-risk population. Among the 36.7 million individuals who were estimated to be HIV-infected in 2015, one in four is estimated to have latent TB infection (LTBI) [2]; HIV+ individuals are 26-fold more likely to develop active TB disease than HIV-individuals [1]. As many as 1.17 million new TB incident cases occurred among PLHIV in 2015, a third of whom were started on antiretroviral therapy (ART).

Increased TB risk is observable as early as HIV seroconversion and further exacerbates as $\mathrm{CD} 4+\mathrm{T}$ cell counts decrease.
Therefore, HIV + individuals have a much higher probability of progressing to active TB disease, although they are not necessarily more infectious to others. These are some of the reasons behind WHO recommendation that all patients with a diagnosis of TB should be offered HIV testing [1].

The management of HIV and TB co-infections is challenging and usually associated with less favourable treatment outcomes. The emergence and spread of drug resistance among Mycobacterium tuberculosis (MTB) strains constitute an even greater threat for an already problematic epidemic, for both clinical and public health reasons. In South Africa where HIV testing and drug susceptibility testing (DST) capacity for MTB is robust, $40-80 \%$ of patients with multidrug-resistant TB (MDR-TB) and extensively drug-resistant TB (XDR-TB) are HIV-infected [3,4]. Other more localised epidemiological "hot-spots" exist in the Russian Federation and Eastern Europe, often in association with injection drug use [5]. In a Latvian cohort of 5200 TB patients, the risk of developing drug-resistant TB was two-fold in HIV-infected individuals [6].

Higher rates of extrapulmonary disease and smear-negative pulmonary disease in HIV-infected subjects limit diagnosis based on sputum examination. Delay in TB diagnosis contributes to poor treatment outcomes amongst HIV-infected patients. The effort to have a culture-based diagnosis of TB is imperative, and

TABLE I

Global prevalence of TB-HIV coinfection [1]

\begin{tabular}{|c|c|c|c|c|c|c|c|}
\hline Region & $\begin{array}{l}\text { TB incidence } \\
\text { (inc TB and HIV) } \\
\text { (per 100,000) }\end{array}$ & $\begin{array}{l}\text { TB HIV coinfection } \\
\text { incidence } \\
\text { (per 100,000) }\end{array}$ & $\begin{array}{l}\text { Mortality of } \\
\text { TB and HIV } \\
\text { (per 100,000) }\end{array}$ & $\begin{array}{l}\% \text { of HIV } \\
\text { status } \\
\text { known }\end{array}$ & $\begin{array}{l}\% \text { of all } \\
\text { TB cases } \\
\text { pulmonary }\end{array}$ & $\begin{array}{c}\% \text { of pulmonary } \\
\text { TB bacteriologically } \\
\text { confirmed }\end{array}$ & $\begin{array}{l}\% \text { of HIV patients } \\
\text { on preventative } \\
\text { treatment for TB }\end{array}$ \\
\hline PAHO (Americas) & 27 & 3,2 & 0,59 & 82 & 85 & 77 & 42 \\
\hline East Mediterranean & 116 & 2 & 0,46 & 17 & 77 & 56 & 40 \\
\hline European & 36 & 3 & 0,54 & 72 & 86 & 61 & 63 \\
\hline SE Asia & 246 & 12 & 3,9 & 52 & 83 & 63 & 8,9 \\
\hline Pacific & 86 & 1,8 & 0,31 & 43 & 92 & 38 & 50 \\
\hline
\end{tabular}


aspiration of lymph node, pleural fluid, as well as blood and urine culture for mycobacteria, have been of additive yield in diagnosing XDR-TB in some HIV-infected cohorts [7].

Once TB is diagnosed in HIV-infected patients, the international consensus favours ART naïve patients to begin ART within 2 weeks since anti-TB treatment initiation if CD $4<50$ cells/ $\mathrm{mm}^{3}$ or if there is significantly advanced disease, and between 2 to 8 weeks if a better immunological profile is observed [8]. Significant challenges exist for the treatment of MDR/XDR-TB in the HIV co-infected population regarding the availability of new drugs and drug-drug interactions (DDIs).

\section{Screening and diagnosis}

The choice of a diagnostic tool for TB depends on the purpose of testing (detecting LTBI, active TB disease or drug resistance), as well as on the clinical conditions of the patient and the local resources available.

\section{Diagnosis of LTBI}

Exposure to MTB leads to two broad outcomes: elimination or persistence of the pathogen. WHO defines Latent tuberculosis infection (LTBI) as "a state of persistent immune response to stimulation by (MTB antigens without any active symptoms)". WHO estimates that the lifetime risk of activation for latent TB is approximately $5-10 \%$. Individuals can have either LTBI or active TB, depending on changes in host immunity and comorbidities, this is considered to be a dynamic continuum. Known factors favouring the development of active disease include HIV-positive status (with a 10-30\% annual risk of developing the active disease), recent contact with an infectious person, homelessness, illicit drug use and initiation of antitumour necrosis factor treatment [1]. The WHO recommends the systematic screening of active TB and LTBI in contacts in HIV-infected patients and provision of appropriate treatment, moreover, efforts towards elimination are being made in low incidence settings [152,153]. Latent TB can be diagnosed with the use of tuberculin skin testing (TST) or interferon gamma release assay (IGRA) tests. In patients with positive TST, the risk of developing active TB increases to $76 \%$ in those who are HIV-positive compared to $10 \%$ in HIV-negative patients [10].

British HIV association (BHIVA), National institute for health and care excellence (NICE) and American centers for disease control and prevention (CDC) have all recommended that latent TB testing should be performed following clinical risk stratification. BHIVA recommends that the following should be taken into account before testing HIV-positive individuals with IGRA: country of origin, duration of antiretroviral treatment, and CD4+ cell count [11].

NICE guidance gives the option of testing with IGRA alone or IGRA and TST in patients who are immunocompromised but, specifically, recommends dual testing with IGRA and TST in PLHIV with CD4+ cell count less than 200 cells $/ \mathrm{mm}^{3}$ [12].
The latest CDC guidelines from 2010 recommend testing for latent TB in all HIV-positive individuals with either IGRA or TST. However, they support the use of IGRA in the BCG-vaccinated and those likely to default TST reading. CDC recommends dual testing if initial testing is negative [13].

Previous guidelines from $\mathrm{CDC}$ and American thoracic society (ATS) in 2000 and by ATS, CDC and infectious diseases society of America (IDSA) in 2005 recommended risk stratification and testing with TST in high-risk groups $[14,15]$. By contrast, guidelines in 2002 from US public health service and IDSA recommended testing all patients with HIV for latent TB with TST. Guidelines from WHO [16] also recommend risk stratification and testing with either IGRA or TST in high-income countries (TB incidence less than 100 cases per 100,000 inhabitants) and just TST in low-income countries [1]. Similarly, the European centre for disease prevention and control (ECDC) guidelines (2011) recommend risk stratification and testing with both IGRA and TST in high-risk patients [17].

The use of TST as a screening tool for latent TB has some distinct disadvantages, such as false positives in those with BCG vaccination and infection with non-tuberculous mycobacteria [18], and false negatives in those with weakened immunity (such as HIV-infected) [19].

IGRAs are more specific in those with previous BCG vaccinations and weakened immunity. IGRAs involve a single blood test, where synthetic peptides interact with $M$. Tuberculosis specific T cells which release interferon gamma [19].

A meta-analysis by Menzies et al. reported that IGRAs are more specific than TST for both positive and negative tests [20]. In 2011, Diel et al. published the results of a systematic review and meta-analysis of studies comparing TST and IGRAs. They concluded that IGRAs are more specific than TSTs and have higher positive and negative predictive values [21].

Despite this, there is limited data on the benefit of either test in HIV-positive individuals, especially those with low CD4 counts. Ayubi et al. published the results of their meta-analysis in 2016 and concluded that there was a fair agreement between TST and IGRAs in those with good CD4 counts. However, a significant limitation in these studies was posed by small sample sizes [22]. Another study showed that in individuals with low CD4 counts IGRAs were more accurate than TST [23].

\section{Diagnosis of active tuberculosis}

TB diagnosis in HIV-infected patients may be challenging, given the higher rates of sputum smear-negative and extrapulmonary disease. Smear-negative, culture-positive pulmonary TB is common and frequently occurs with advanced immunosuppression [32]. Cavitary pulmonary cases are more likely to be smear positive, whereas a negative smear in a patient with minimal findings on chest radiograph is not unusual, and does not rule out active TB. Testing for TB infection in those with a known HIV diagnosis is cost-effective even in low-incidence settings [33]. 
To detect active TB disease, four main modalities are used: imaging (chest radiographs and computerised tomography), microscopy (smears for acid-fast bacilli - AFB), culture-based methods and molecular tests. While chest radiography is used for screening and monitoring, it lacks specificity, therefore, definitive active TB disease diagnosis requires a microbiological method.

Diagnosis of active TB is of paramount importance in HIV patients starting ART. Standard investigations for HIV-negative patients with pulmonary TB involve smear microscopy and culture of sputum samples. Patients with HIV infection, especially those with weak immunity, can have a lower bacillary burden and therefore, the sensitivity and specificity of the smear microscopy can be inadequate, and waiting for cultures can take up to 8 weeks to confirm a diagnosis [24].

\section{Symptom screening}

Previous WHO guidelines suggested that a cough in a HIV patient should alert the clinician to investigate for TB; however, the sensitivity of this test is inadequate at 40-60\% [25]. It has been found that combining multiple classical symptoms (cough, weight loss, fever and night sweats) increases the sensitivity of detecting TB with one definite symptom-giving a sensitivity of $75 \%$ and specificity of $50 \%[26,27]$.

Symptom-based screening is limited for establishing a diagnosis of TB in HIV-infected patients. Cough, fever or night sweats $>3$ weeks in the preceding month had a sensitivity and specificity of $93 \%$ and $36 \%$, respectively [34]. However, the absence of symptoms such as fever, night sweats, weight loss, and cough had a $97.7 \%$ negative predictive value to exclude active TB infection [27]. In one study, almost a quarter of patients who were diagnosed with pulmonary TB reported no cough but were able to provide a sputum sample [35] (table II). ART initiation can be problematic in unmasking undiagnosed TB and areas of high burden of TB disease; up to $40 \%$ of TB cases diagnosed within 4 months of ART initiation were thought to be due to subclinical infection before ART treatment [28]. This has led to guidelines being changed to look for all those mentioned above four classic TB symptoms and if any is present to investigate further for active TB disease. In areas of high disease, burden up to $20 \%$ of those starting ART had undiagnosed TB due to inadequate screening programmes [25].

Early diagnosis of TB in HIV patients is imperative as it is known to reduce morbidity, mortality, IRIS incidence rates as well as nosocomial transmission of MTB.

\section{Tuberculin skin testing}

TST in HIV-positive individuals, defined as positive by a skin induration $\geq 5 \mathrm{~mm}$ [36] is more likely to be falsely negative, especially with lower CD4+ cell counts. TST positivity varies by CD4 stratum: $12.4 \%$ with $\mathrm{CD} 4+<200$; $28.4 \%$ with CD4+ between 200 to 499; and 37.4\% with CD4 > 500 [36]. TST has no value for diagnosing active TB in adults in areas where
TABLE II

Features of tuberculosis in HIV+ negative patients [148]

\begin{tabular}{|c|c|c|}
\hline & $\begin{array}{l}\text { HIV+ } \\
\text { individuals }\end{array}$ & $\begin{array}{l}\text { HIV- } \\
\text { individuals }\end{array}$ \\
\hline Respiratory symptoms & +++ & +++ \\
\hline Extrapulmonary disease & +++ & + \\
\hline Cavitary lung disease & + & +++ \\
\hline $\begin{array}{l}\text { Atypical features on chest } \\
\text { radiograph }\end{array}$ & +++ & $+/-$ \\
\hline Negative tuberculin skin test & ++ & $+/-$ \\
\hline AFB smear positivity & $+/-$ & ++ \\
\hline Adverse drug reactions & ++ & $+/-$ \\
\hline Mortality rate & +++ & $+/-$ \\
\hline $\begin{array}{l}\text { Relapse after completion } \\
\text { of treatment }\end{array}$ & ++ & \\
\hline
\end{tabular}

AFB: acid fast bacilli.

TB prevalence is high. C-Tb, a novel TST utilising ESAT- 6 and CFP10 antigens, has similar sensitivity compared with QFT-GIT for the diagnosis of MTB infection. However, sensitivity is reduced in HIV-infected patients with severe immunosuppression [37]. In low TB prevalence settings, a positive TST in a patient with symptoms and signs suggestive of TB may support the diagnosis but when negative it does not exclude active disease.

\section{IGRAs}

IGRAs are blood tests approved for the diagnosis of LTBI (the two most widely used are T-Spot.TB and QuantiFERON Gold In-Tube QFT-GIT). They are more accurate than TST in BCG-vaccinated subjects and appear to retain sensitivity at lower CD4+ cell counts, [38] however, T-SPOT seems to be less affected by lower CD4+ cell counts than QFT-GIT and TST [39]. Evidence regarding the role of IGRA to predict the presence of active TB in HIV+ individuals is lacking.

\section{Microbiological evaluation Sputum specimens for smear and culture}

In a recent study, Pouched rats detected $60 \%$ of TB patients otherwise missed by clinics, but identifiable with concentrated smear microscopy. The rats could potentially make a difference in low-resource settings [40]. Microscopy, however, remains an essential part of TB diagnosis. At least two sputum samples should be collected for AFB smear and culture, preferably on different days and at least one being an early morning specimen. The incremental yield of a third sputum smear may be limited to $2 \%$ to smear alone, but it reaches $10 \%$ for liquid cultures; nevertheless, the yield of sputum smear decreases with lower CD4+ counts [41]. In HIV-positive individuals, sputum 
smear microscopy detects only $22-43 \%$ of active TB disease [42]. Given the high rates of AFB smear-negative disease, culture is essential to confirm TB and for drug susceptibility testing in HIV+ patients.

In a study, the Mycobacteria growth indicator tube (MGIT) liquid culture-confirmed $71 \%$ of TB cases, and the use of 3 MGIT cultures gave the highest yield, identifying $98 \%$ of TB cases in a time range of 7 to 28 days [41]. Drug susceptibility tests (DSTs) are available within 10-21 days after culture isolation. Bronchoscopy with lavage and biopsy can be useful in the evaluation of individuals with abnormal chest imaging and negative sputum smears. Histopathology and AFB smear of specimens obtained by bronchoscopy can make a suggestive diagnosis of TB in more than a third of individuals, similar to the yield in HIV-negative cases with smear-negative pulmonary TB [43]. Positive cultures for MTB provide a definitive diagnosis of active TB. However, approximately $15 \%$ of reported TB cases among HIV-positive individual are culture negative [44].

Induced sputum by ultrasonic nebulization with hypertonic saline may represent a valid alternative to bronchoscopy in patients unable to expectorate or with repeatedly negative smears on spontaneous sputum [45]. Thoracentesis and pleural biopsy are necessary for the diagnosis of pleural TB; cell predominance and LDH, protein, glucose and adenosine deaminase (ADA) levels do not significantly differ in the pleural fluid of HIVinfected respect to uninfected patients with pleural TB $[46,47]$. Biopsies demonstrate AFB in $69 \%$ of patients and granulomata in $88 \%$. However, granulomas are often poorly formed in HIVpositive patients [48].

Samples from extrapulmonary sites should be sought to confirm extrapulmonary or disseminated TB. HIV patients with extrapulmonary signs or symptoms should have samples from the suspected site collected to increase the likelihood of TB diagnosis. However, incremental yield of extrapulmonary samples in HIV-infected patients routinely screened for TB is low [41]. Lymph node aspiration of enlarged peripheral lymph nodes can provide rapid diagnosis of TB. Fine needle aspiration was helpful in $77 \%$ of cases, and biopsy with culture for MTB increased the yield to $96 \%$ in one study [49]. In patients with miliary disease and negative sputum examination, bone marrow biopsy, as well as blood cultures, should be performed [50]. Blood cultures are frequently negative but can be positive in up to half of HIV-positive patients with disseminated disease and $\mathrm{CD} 4+<100 / \mathrm{mm}^{3}$ [49]. Renal TB is rare, but the genitourinary tract is often involved in disseminated TB. In one series, 61 of 79 (77\%) HIV-infected patients with extrapulmonary TB whose urine was sent for culture grew M. tuberculosis [50]. Stool cultures are helpful to diagnose Mycobacterium avium complex (MAC) infection but are less useful for diagnosing TB [41]. CNS is often involved in disseminated TB [51]. There is a low threshold for collecting CSF given that several pathologies can affect the central nervous system in AIDS. Liver biopsy has a very high yield in disseminated TB [50], but the diagnosis of TB can usually be made by less invasive means. Multiorgan involvement was found to be the cause of death in $92.3 \%$ HIV-patients in a recent study [52].

\section{Rapid methods}

Modern diagnostic tests are now available, but they also have their pitfalls. The use of PCR is becoming more accessible and proving to be a valuable diagnostic tool in early detection of TB disease. The well known GeneXpert MTB/RIF (Cepheid) can give a diagnosis of TB in less than 2 hours, requiring limited laboratory skills, has specificity result of $100 \%$ and can increase detection rate by $45 \%$ when compared to smear microscopy alone $[29,30]$. In particular, WHO strongly recommends Xpert MTB/RIF as an initial diagnostic test in these patients in adults and children presumed to have MDR-TB or HIV-associated TB [53]. Owing to superior accuracy than sputum smear microscopy $[54,55]$, the WHO recommends Xpert MTB/RIF as a first-line test in all adults or children suspected of having active TB disease [53]. Xpert MTB/RIF has paved the way for meeting a key component of the first pillar of the END-TB Strategy; early diagnosis of TB including universal drug susceptibility testing [56]. The Xpert MTB/RIF assay is a nucleic acid amplification test that can rapidly identify the presence of MTB complex and rifampin resistance. In a systematic review, sensitivities in sputum smear positive and negative patients with positive cultures were $98 \%$ and $67 \%$, respectively, with a specificity of $99 \%$, while sensitivity of $95 \%$ and specificity $98 \%$ were identified for rifampicin resistance detection [57]. A recent meta-analysis shows the pooled sensitivity and specificity for detection of smear-negative pulmonary tuberculosis in sputum smear-negative and high TB-HIV settings were 67\% and 98\% respectively [58]. The Xpert MTB/RIF assay should reduce time to diagnosis and initiation of effective therapy. A significant limitation of the Xpert MTB/RIF assay is its inability to determine which patients with pulmonary TB have sputum positive for AFB on microscopy, used to guide infection control practice, contact tracing, and monitor response to treatment. In a study including 496 patients with suspected TB in South Africa, the cycle threshold values were moderately useful for ruling out smear positivity (negative predictive value $80 \%$ ), although the clinical utility for ruling in smear positivity was low [59]. The Xpert MTB/RIF assay is not of value in monitoring the response to therapy, and false positives may occur in people previously treated for TB [60]. The Xpert MTB/RIF is less sensitive with smear-negative samples, but its sensitivity can be increased to $90 \%$ with the addition of 3 sputum specimens [61].

Antigen testing is becoming more widely available also in resource-limited countries. The most common test is urinary lipoarabinomannan (LAM). Urine-based detection of mycobacterial antigen LAM is a lateral flow assay for diagnosis of hematogenous disseminated TB. Use of LAM for diagnosis of TB in 
HIV-infected adults may be associated with a reduction in mortality [66]. LAM has shown to be of more diagnostic value compared to smear testing, in particular among those with CD4+ cell counts $<100$ cells per microliter [31]. LAM has high specificity (88\% to 99\%) [62] and is most sensitive in HIVinfected patients with low CD4+ cell counts [63]. The overall sensitivity of urinary LAM testing in culture-positive TB patients with HIV infection is low (40-60\%) [64], but increases to 67$85 \%$ in those with CD4 counts of $<50$ cells/ $\mu \mathrm{L}$ [65]. Urine LAM has been proposed as a "rule in" test but appears inadequate as a stand-alone "rule out" test for TB.

Where possible drug susceptibility testing (DST) to first-line agents should be performed in all HIV+ patients with culturepositive TB. DST optimise the efficacy of therapeutic regimens and decrease transmission of drug-resistant TB [67].

\section{Management \\ LTBI treatment}

Isoniazid monotherapy has a protective effect on reactivation of LTBI. In a study by Golub et al. [68], the protective effect in HIVinfected individuals lasted for 2 to 4 years in endemic countries and more than 19 years in countries with low incidences $[68,69]$. BHIVA guidelines recommend treating LTBI in HIV+ patients with daily isoniazid $(\mathrm{H})$ with pyridoxine as the preferred method for 6 months or, an alternative, combination of rifampicin (R) and $H$ for 3 months. NICE, however, recommends either 6 months of $H$ (with pyridoxine) or 3 months of $\mathrm{R}$ and $\mathrm{H}$ in combination. $\mathrm{CDC}$ recommends daily $\mathrm{H}$ for nine months as the preferred treatment with twice weekly isoniazid as an alternative. The combination of $\mathrm{H}$ and rifapentine is not currently recommended by $\mathrm{CDC}$ in individuals with HIV on ART for risk of drug-drug interactions. WHO (2016) recommends the use of at least 6 months of preventive $\mathrm{H}$ monotherapy to HIV+ individuals, with a positive or unknown TST, in resource-constrained settings with high TB incidence regardless of ART or degree of immunosuppression [16]. ART reduces active TB disease incidence by fostering immune reconstitution; the lower the CD4+ T cell count, the higher the ART-associated protection [70]. The combined use of ART and $\mathrm{H}$ preventive treatment has shown to be additive in reducing active TB disease incidence and severe illness among HIV-positive individuals $[71,72]$. The risk of developing active TB disease remains two-fold higher in HIV-positive individuals even if CD4+ T-cell count is within normal range [28], and they can still develop active TB disease even if they are receiving ART. Flexible interventions tailored to respond to the local context and needs of the population to ensure adherence to, and completion of, LTBI treatment should be applied [73].

\section{Treatment of drug-susceptible TB in HIV patients}

Some of the top medical organisations on the planet have published or endorsed guidelines and recommendations regarding the treatment of TB and HIV in co-infected patients [74-78].
The most recent work on this topic was a publication jointly sponsored by the ATS, CDC, infectious diseases society of America (IDSA), European respiratory society (ERS), the WHO, and the Union and others [78]. Attempting to answer the most frequent questions clinicians face, we have summarised the recommendations in which there is general agreement. These must be adapted to local needs, resources and barriers.

\section{How does the treatment of TB in HIV co-infected patients differ?}

Treatment of susceptible pulmonary TB in HIV co-infected patients follows the same basic principles used for TB in HIVuninfected patients: multiple drugs, fixed dose combinations (FDC) and a two-phase regimen administered under directly observed therapy (DOT). Said approach is sufficient to rapidly decrease transmission and improve outcomes such as cure and relapse rate. Additionally, development of drug resistance is minimised [74-79]. The main differences in TB treatment for $\mathrm{HIV}+$ patients are: daily medicine intake during the two phases is preferred, and interactions with ART and other medications must be taken into account; since extensive disease and extrapulmonary TB are common, the length of therapy and monitoring of outcome must be individualised, and usually regimens longer than 6 months are used; the presence of other co-infections or kidney and liver disease may also complicate the scenario [7483].

\section{When should TB therapy be started?}

There is a general agreement that TB treatment must be started as soon as possible, irrespective of CD4+ cell count [74-79]. Early onset of treatment decreases mortality and transmission of TB. Empirical treatment is justified by clinical suspicion, in spite of bacteriological confirmation. Nevertheless, every effort to rule out resistant TB should always be made before starting therapy by employing culturing and when available, molecular tests.

\section{Antiretroviral therapy}

The WHO recommends that all HIV-positive individuals with drug-sensitive or drug-resistant active TB disease should begin ART within the first 2 months of TB treatment, regardless of their CD4+ T cell count. Randomised controlled trials [54,84-87], systematic reviews and meta-analyses $[88,89]$ confirm the benefit of combining HIV and TB therapy in reducing mortality rates. Preferred ART regimens are described in the 2016 WHO guidelines [16]; in adults, first-line treatment comprises a combination of two nucleoside reverse-transcriptase inhibitors and a non-nucleoside reverse-transcriptase inhibitor or an integrase inhibitor.

HIV + patients with drug-sensitive or drug-resistant active TB disease and $C D 4+$ cell counts of $<50$ cells $/ \mu \mathrm{L}$ should receive ART within 2 weeks of initiating TB treatment [16] unless there is a concomitant diagnosis of TB meningitis. In these patients, ART should be delayed to 2 months after the start of TB treatment to reduce the risk of severe adverse effects [89]. 


\section{Which drug regimen should be used?}

Unless risk factors for resistant TB are present (retreatment, high incidence of primary resistant TB, exposure to resistant cases), a 4-drug-regimen using $\mathrm{H}, \mathrm{R}$, Ethambutol (E) and Pyrazinamide ( $\mathrm{Z}$ ) is the best choice. $R$ can be replaced by rifabutin (RFB). This regimen uses an intensive phase with the four drugs followed by a continuation phase with only $\mathrm{H}$ and $\mathrm{R}$. During the continuation phase; daily administration is recommended over intermittent dosing [76,79-84]. Doses recommended are presented in table III. The intensive phase lasts 2 months, but can be extended when the bacteriologic response is slow. Continuation phase should last at least 4 months, but many experts recommend prolonging to 7 months, mainly in those cases with extensive diseases, cavities and slow bacteriologic response. Central nervous system disease, meningitis and bone TB may need regimens of 12 months or more. The standard 4-drugregimen can be used safely during pregnancy and breastfeeding $[76,79]$. It is important to note that WHO recommends that if daily dosing is not feasible during the continuation phase, intermittent therapy three times weekly could be an acceptable alternative only if DOT is warranted [76]. Once or twice a week regimens should not be used to treat TB-HIV co-infection [90].

\section{How should the patients be monitored?}

Monitoring during treatment should focus on clinical-bacteriological responses and actively monitor for drug-related adverse events. Bacteriological follow-up is difficult given that many of these patients are sputum smear and culture negative. In those with basal AFB sputum positivity, follow-up smears once or twice a month are useful to evaluate early response to therapy. Positive cultures after 3-4 months of therapy announce treatment failure and resistance should then be addressed.

\begin{tabular}{|c|c|c|}
\hline & Intensive phase & Continuation phase \\
\hline Standard treatment & $\begin{array}{l}H+R+E+Z^{1} \\
\text { Daily for } 2 \text { months }\end{array}$ & $\begin{array}{c}H+R^{1} \\
\text { Daily for } 4-7 \text { months }\end{array}$ \\
\hline Alternative treatment & $\begin{array}{l}\mathrm{H}^{\mathrm{H}+\mathrm{RFB}{ }^{1}} \\
\text { Daily for } 2 \text { months }\end{array}$ & $\begin{array}{c}\mathrm{H}+\mathrm{RFB}^{1} \\
\text { Daily for } 4-7 \text { months }\end{array}$ \\
\hline Alternative treatment & $\begin{array}{l}H+R+E+Z^{1} \\
\text { Daily for } 2 \text { months }\end{array}$ & $\begin{array}{c}H+R^{2} \\
\text { 3-times a week } \\
\text { for } 4-7 \text { months }\end{array}$ \\
\hline
\end{tabular}

${ }^{1}$ Recommended daily dose in adults. $\mathrm{H}: 5 \mathrm{mg} / \mathrm{kg}$ (usually $300 \mathrm{mg}$ ); R: $10 \mathrm{mg} / \mathrm{kg}$ (usually $600 \mathrm{mg}$ ); RFB: $5 \mathrm{mg} / \mathrm{kg}$ (usually $300 \mathrm{mg}$ ); E: $15-25 \mathrm{mg} / \mathrm{kg} ; \mathrm{Z}: 30-40 \mathrm{mg} / \mathrm{kg}$ up to $2 \mathrm{~g}$. Four drugs fixed-dose combination usually contains: H $300 \mathrm{mg}, \mathrm{R} 600 \mathrm{mg}$, E $1200 \mathrm{mg}$, Z $1600 \mathrm{mg}$.

23-times a week dosing: $\mathrm{H}: 15 \mathrm{mg} / \mathrm{kg}$ up to $900 \mathrm{mg}$, R: same as for daily dose, $600 \mathrm{mg}$. Two drugs fixed-dose combination usually contains: H 800 or $900 \mathrm{mg}$ and R $600 \mathrm{mg}$.

${ }^{3}$ Only if DOT is warranted.
Symptoms are useful indicators of improvement or worsening, but periodic radiographic and laboratory studies are needed to have a full evaluation [74]. Offering adequate DOT strategies must be a top priority in any TB program since it is a worldwide standard of practice $[76,79,90]$. The main toxicity related to $H, R$ and $Z$ is hepatitis; discontinuation of all the drugs and rechallenging them in a progressive fashion is a useful approach, and the authors recommend starting with $\mathrm{R}$ and $\mathrm{E}$ first. If intolerance to any of the drugs is observed, patients must be treated as resistant to such drug [74] and possibly another drug added to the regimen, most commonly a quinolone.

\section{Management of MDR and XDR TB in HIV co-infected patients}

The spread of drug-resistant forms of TB is a significant threat at the global level and represents an even greater scourge in areas with a high HIV prevalence [1]. The burden of MDR and XDR-TB among PLHIV is likely to be underestimated due to the limited laboratory capacity that remains a considerable challenge in low- and middle-income countries, where mycobacterial culture is only seldom available. The rising implementation of rapid biomolecular tests such as Xpert MTB/Rif is significantly improving the case detection rate, though such assays do not allow for a comprehensive picture of drug-resistance patterns that can only be obtained through DST on solid or liquid culture [57,92]. MDR-TB is caused by mycobacterial strains resistant to at least both $\mathrm{H}$ and $\mathrm{R}$, while XDR-TB corresponds to a multidrug-resistant pattern with additional resistance to fluoroquinolones and at least one second-line injectable agent. As a consequence, such cases cannot be treated with the standard first-line regimen and are associated with a much poorer outcome, both in short and the long-term [93]. Moreover, second-line drugs are characterised by higher toxicity and lower tolerability and must be used for longer periods (a total of approximately 18-20 months), although shorter regimens of up to 12 -month duration are now available and can be adopted under specific conditions [93-96,150,151].

HIV-positive individuals are among the most at-risk groups for $\mathrm{M} / \mathrm{XDR}-\mathrm{TB}$, as a consequence of inappropriate management of concomitant TB, which often goes unrecognised or is inadequately treated thus promoting the selection of further resistances. Also, malabsorption of some anti-TB drugs is believed to be more common among PLHIV, being responsible for subtherapeutic plasmatic concentrations and therefore reduced efficacy [97]. The cumulative knowledge of pharmacokinetics/pharmacodynamics of antituberculosis agents has brought therapeutic drug monitoring (TDM) in patient care. Logistical problems related to conventional sampling had till recently limited the use of TDM in the clinical routine. Dried blood spot (DBS) compared with venous blood sampling has the advantages of simpler sampling and transportation to the lab, widening the appeal and applicability of TDM. Also, DBS with its lower 
biohazard status can be safely performed in a higher HIV prevalence areas [98]. Use of TDM could lead to more effective and less toxic regimens and reduce drug-resistance [99-102]. Whether HIV infection is an independent risk factor for the emergence of multidrug-resistant mycobacterial strains is still a matter of debate [103-105]. Hence, early detection of active TB and the quick identification of drug-resistant strains are pivotal to increase the chances of success, provided that an optimal integration of TB and HIV services is ensured [75]. The combination of anti-TB treatment and ART may become a big challenge for the clinician coping with the management of DDIs and adverse events in addition to the several complications of AIDS [106,107].

While many studies have already demonstrated that ART is highly beneficial for dually infected individuals, leading to a considerable improvement in survival, evidence for MDR-TB patients who are HIV-infected is still very limited [108-111]. According to a systematic review published in 2012, the effect of ART is likely to be similar in this population irrespective of the level of immunodeficiency, though greater benefits are expected among patients with an advanced stage of HIV disease (i.e. with a $\mathrm{CD} 4+$ cell count below $50 / \mu \mathrm{L}$ ) [112]. In particular, the use of ART was found to be associated with higher rates of sputum smear conversion and shorter time to conversion as well, probably reflecting a positive effect on the immune response to mycobacteria [112].

Antiviral and anti-TB drugs must be chosen with caution by taking into serious consideration the potential overlapping toxicities and the pill burden which may be responsible for a sub-optimal adherence to treatment $[113,114]$. Among the most commonly observed toxic effects are renal and hepatic toxicity. For instance, the co-administration of tenofovir (which is part of the recommended first-line ART regimens) with aminoglycosides may lead to severe nephrotoxicity, while liver dysfunction can be favoured by non-nucleoside reverse transcriptase inhibitors (NNRTIs) (above all nevirapine [NVP] which is widely used in resourcelimited settings) or some protease inhibitors (PIs) especially when associated with some anti-TB second-line molecules such as ethionamide/prothionamide or para-aminosalicylic acid. Moreover, the concomitant use of some nucleoside reverse transcriptase inhibitors (NRTIs) such as zidovudine with linezolid, which is being increasingly utilised in M/XDR-TB regimens, should be conducted under close monitoring due to the resulting enhanced myelosuppression. The integrase inhibitor class of antiretroviral drugs offer less interaction with second-line TB medications but are not routinely available in TB endemic settings.

The WHO recently recommended the use of a shorter MDR-TB regimen which allows for the reduction of treatment duration from 18-22 months to 9-12 months. This represents a paradigm shift in the management of drug-resistant cases, potentially simplifying and delivering greater access and wider dissemination of life-saving therapy to a larger number of people in resource-limited settings, possibly reducing defaults and improving completion rates through better adherence and tolerance to a shorter regimen $[93,95]$. Unfortunately, such short regimen has some limitations depending on the resistance pattern of the isolated strains [95].

On the novel anti-TB drugs that were recently approved by the WHO, an interim cohort analysis carried out in South Africa on $91 \mathrm{M} /$ XDR-TB patients, 59\% of whom were HIV-positive, suggests that bedaquiline may be safe and effective regardless of HIV status [115]. In this study, all patients who were receiving an efavirenz-based ART regimen when started on bedaquiline were switched to either NVP or lopinavir/ritonavir (LPV/r), in accordance with currently available pharmacokinetic data, though NVP seems to be safer than LPV/r and does not require any dose adjustment $[116,117]$. Although there is even less evidence concerning the use of delamanid in association with antiretroviral agents, no significant DDIs have been flagged up to now [118].

There is accumulating evidence for the safety and efficacy of bedaquiline in HIV-infected patients with XDR-TB. The majority of patients in the South African early access program for bedaquiline were HIV-infected, and of those remaining on bedaquiline with 6 months of follow-up, 48 (76\%) had either cultureconverted or remained culture-negative, a significant improvement from historical norms [119]. Formal trials of delamanid have to date enrolled very few patients with HIV infection and none on ART [120]. The phase 3 trial of the all-oral regimen of bedaquiline, pretomanid, and linezolid (BPaL) does include HIVinfected patients, but with CD4+ cell count- and ART regimenbased exclusions limiting the number of those participants who would belong to the most important target group $[120,121]$. Initial data from this study was presented at the 47th Union conference and reported that BPaL could treat XDR-TB in 6 months. The interim results for the first 15 participants enrolled in the study, of whom 7 were HIV+, showed that 12 of them completed 6 months of therapy. The majority were culture negative by week 8 . As of October 2016, 30 patients have now completed 6 months of treatment and all have sputum converted. To date, there have been no relapses. However, the study is small and still ongoing. Four patients have died, however substantially lower mortality than ever reported before [122] (see table IV for current drug trials).

In summary, the best approach to M/XDR-TB in people living with HIV has yet to be defined. However, a personalised approach appears to give the best outcomes [123], with careful clinical and laboratory monitoring remaining essential for the correct management of these complex cases. Infection control measures need to be appropriately implemented to limit transmission to other susceptible individuals attending the same health facilities of TB-HIV coinfected patients, and active case finding must be routinely put in place, especially in high-burden areas to promote early diagnosis and treatment. 
TABLE IV

Current drug trials for TB/HIV (update at Oct 23rd, 2016) [120]

\begin{tabular}{|c|c|c|c|c|c|}
\hline $\begin{array}{l}\text { Trial title / } \\
\text { identifier }\end{array}$ & Study design & $\begin{array}{l}\text { Estimated } \\
\text { enrolment } \\
\text { (patients) }\end{array}$ & Objective & Involved countries & Study period \\
\hline $\begin{array}{l}\text { NCT02178592 } \\
\text { (ING117175) }\end{array}$ & $\begin{array}{c}\text { Phase IIIb, randomized, } \\
\text { open-label study }\end{array}$ & 125 & $\begin{array}{c}\text { To assess safety and efficacy of DTG versus EFV } \\
\text { associated with two NRTIs in TB/HIV co- } \\
\text { infected adult patients }\end{array}$ & $\begin{array}{l}\text { Argentina, Brazil, } \\
\text { Mexico, Peru, Russian } \\
\text { Federation, South } \\
\text { Africa, Thailand }\end{array}$ & 2015-2019 \\
\hline $\begin{array}{l}\text { NCT02273765 } \\
\text { (REFLATE TB2) }\end{array}$ & $\begin{array}{c}\text { Phase IIIb, randomized, } \\
\text { open-label study }\end{array}$ & 460 & $\begin{array}{l}\text { To assess non-inferiority of RAL } 400 \mathrm{mg} \text { bid } \\
\text { compared to EFV } 600 \mathrm{mg} \text { qd associated with } \\
\text { TDF+3TC in ART-naïve TB/HIV adult patients }\end{array}$ & $\begin{array}{l}\text { Brazil, France, Ivory } \\
\text { Coast, Mozambique, } \\
\text { Vietnam }\end{array}$ & 2015-2019 \\
\hline NCT02906007 & $\begin{array}{l}\text { Phase I/II, open-label, } \\
\text { single arm study }\end{array}$ & 72 & $\begin{array}{l}\text { To evaluate the pharmacokinetics, safety and } \\
\text { tolerability of BDQ-containing MDR-TB } \\
\text { regimens in HIV-infected infants, children and } \\
\text { adolescents }\end{array}$ & Not reported & $2016-2020$ \\
\hline NCT01700790 & $\begin{array}{l}\text { Phase IV, open-label, } \\
\text { single arm study }\end{array}$ & 12 & $\begin{array}{c}\text { To evaluate the pharmacokinetic interactions, } \\
\text { short term safety and efficacy of standard dose } \\
\text { LPV/r } 400 \mathrm{mg} / 100 \mathrm{mg} \text { bid + } 3 \text { tablets of RTV } \\
100 \mathrm{mg} \text { in association with rifampicin- } \\
\text { containing anti-TB regimen in TB/HIV adult } \\
\text { patients }\end{array}$ & Brazil & 2012-2018 \\
\hline NCT02583048 & $\begin{array}{c}\text { Phase II, randomized, } \\
\text { open-label study }\end{array}$ & 84 & $\begin{array}{l}\text { To evaluate the safety, tolerability and } \\
\text { pharmacokinetics of BDQ and DLM, alone or in } \\
\text { combination, among HIV-infected and } \\
\text { uninfected adult patients with MDR-TB }\end{array}$ & South Africa & $2016-2017$ \\
\hline NCT01751568 & $\begin{array}{l}\text { Phase I/II, open-label, } \\
\text { single-arm study }\end{array}$ & 72 & $\begin{array}{l}\text { To assess the safety, tolerability and } \\
\text { pharmacokinetics of RAL in TB/HIV co-infected } \\
\text { children aged } 2 \text { to } 11 \text { years }\end{array}$ & South Africa & 2014-2019 \\
\hline NCT02415985 & $\begin{array}{l}\text { Phase II, open-label, } \\
\text { randomized study }\end{array}$ & 40 & $\begin{array}{l}\text { To evaluate the pharmacokinetics of rifabutin } \\
150 \mathrm{mg} \text { once daily versus rifabutin } 300 \mathrm{mg} \\
\text { thrice weekly in association with LPV/r } 400 / \\
100 \mathrm{mg} \text { in TB/HIV adult patients }\end{array}$ & Thailand & 2015-2017 \\
\hline $\begin{array}{l}\text { NCT01637558 } \\
\text { (DATiC) }\end{array}$ & $\begin{array}{l}\text { Phase IV, open-label, } \\
\text { non-randomized study }\end{array}$ & 240 & $\begin{array}{l}\text { To evaluate the pharmacokinetics of NVP or } \\
\text { LPV/r ( } 4: 1 \text { ratio) in TB/HIV co-infected children } \\
\text { aged } 1 \text { month to } 12 \text { years receiving rifampicin- } \\
\text { containing anti-TB treatment }\end{array}$ & Malawi, South Africa & 2012-2017 \\
\hline NCT02832778 & $\begin{array}{l}\text { Phase I, open-label, } \\
\text { non-randomized study }\end{array}$ & 35 & $\begin{array}{c}\text { To evaluate the pharmacokinetics of EFV } \\
\text { associated to RIF and INH in TB/HIV co-infected } \\
\text { adult patients }\end{array}$ & Not reported & 2016-2017 \\
\hline $\begin{array}{l}\text { NCT02333799 } \\
(\text { Nix-TB) }\end{array}$ & $\begin{array}{l}\text { Phase III, open-label, } \\
\text { single arm study }\end{array}$ & 200 & $\begin{array}{c}\text { To evaluate the efficacy, safety, tolerability and } \\
\text { pharmacokinetics of BDQ plus PA- } 824 \text { plus LZD } \\
\text { after 6-9 months of treatment in M/XDR-TB } \\
\text { patients aged } 14 \text { or older with or without HIV- } \\
\text { infection }\end{array}$ & South Africa & $2015-2021$ \\
\hline
\end{tabular}

3TC: lamivudine; ART: antiretroviral therapy; BDQ: bedaquiline; DLM: delamanid; DTG: dolutegravir; EFV: efavirenz; HIV: human immunodeficiency virus; INH: isoniazid; LZD: linezolid; LPV/r: Iopinavir/ritonavir; MDR-TB: multidrug-resistant tuberculosis; NRTI: nucleoside reverse transcriptase inhibitor; RAL: raltegravir; RIF: rifampicin; RTV: ritonavir; TDF: tenofovir disoproxil fumarate; XDR-TB: extensively drug-resistant tuberculosis.

\section{HIV-TB special topics}

The management of HIV-TB is complicated by several factors; firstly, DDIs between TB drugs and ART makes it difficult to design safe and effective regimens, which can cause severe adverse effects, such as hepatotoxicity and neurotoxicity.
Secondly, in restoring immunity, ART can trigger the immune reconstitution inflammatory syndrome (IRIS), whereby the host inflammatory response to MTB infection is disproportionate and worsens the patient's status. Last but not least, TB in HIV is more likely to recur. 


\section{HIV and TB drug interactions}

Most HIV drug class are metabolised through the intestine and liver either undergoing phase 1 oxidative metabolism via the cytochrome (CYP) P450 enzyme system and some undergoing phase 2 biotransformation with glucuronidation, via the uridine diphosphate glucuronosyltransferase (UGT) enzyme pathways. Antiretroviral drugs, as well as being substrates of CYP 450, can inhibit and induce this enzyme system. Rifamycins are potent inducers of the CYP enzyme system (in particular CYP 3A4 and CYP 2C). $R$ is the most potent inducer, RFB is $60 \%$ less powerful than R. RFB (not rifampicin) is also a substrate of CYP 3A4. This can lead to bi-directional pharmacokinetic interactions and subtherapeutic antiretroviral drug levels, leading to HIV treatment failure or sub-therapeutic rifamycin drug levels and TB treatment failure [124].

$R$ also induces UGT 1A1. Integrase inhibitors are metabolised by this pathway [125]. Rifamycins induce P-glycoprotein transporter via the intestine, impacting absorption and metabolism of some HIV drugs [126]. Rifapentine (RPT) is not recommended for TB treatment in HIV-infected patients, and there is a paucity of data on the PK of RPT in the context of ART.

NRTIs are not extensively metabolised by CYP P450. There are no dosage adjustments required to NRTIs when co-administered with anti-TB therapy.

NNRTIs globally available are efavirenz and NVP. NVP is extensively metabolised via CYP 3 A4 and induces CYP 3A4, leading to a potential for bi-directional DDIs via the CYP $3 A 4$ pathway. Pharmacokinetic studies demonstrate approximately 30-40\% reduction in serum NVP levels when co-prescribed with R. Data suggests that NVP based regimen in the face of TB therapy is inferior to an efavirenz based regimen, and should be prescribed with caution [127].

Efavirenz is primarily metabolised via the CYP 2B6 iso-enzyme. There is wide pharmacogenetic variability in CYP 2B6 in individuals and thus, wide variability of efavirenz levels when coprescribed with R. Individuals carrying the T/T genotype (more common in black populations) of CYP 2B6 demonstrate higher plasma levels of efavirenz, which can lead to increased levels of neuropsychiatric side effects [128].

Co-administration of efavirenz and $\mathrm{R}$ can lead to a reduction in efavirenz levels of up to $30 \%$. Earlier guidelines suggested an upward dose adjustment of efavirenz to $800 \mathrm{mg}$ once daily (standard dose in $600 \mathrm{mg}$ once daily) when prescribed with $\mathrm{R}$, assuming a body weight above $60 \mathrm{~kg}$ [11]. Recent data has suggested that there is little dose adjustment required to efavirenz due to the wide genotypic variation in CYP $2 \mathrm{~B} 6$ and body weight variability of drug distribution [128]. Efavirenz is the preferred NNRTI for TB-HIV patients.

Protease inhibitors (PIS) inhibit CYP 3A4. However, the induction of CYP $3 A 4$ by $R$ is far more powerful. This leads to an overall lowering of the concentration of PIs to sub-therapeutic levels; data demonstrates up to $>90 \%$ reduction in lopinavir levels [129]. Co-prescribing of $R$ and PIs is not recommended. $\mathrm{RFB}$, due to its lower potency of induction, is the recommended rifamycin to be prescribed with PIs and no dose adjustment of the $\mathrm{PI}$ is required. RFB is a substrate of CYP $3 \mathrm{~A} 4$, the inhibition of CYP $3 \mathrm{~A} 4$ by PIs can lead to increased RFB levels and drug toxicity (anterior uveitis, neutropenia). A dose reduction of rifabutin is recommended. Previous recommendations were to prescribe $150 \mathrm{mg}$ alternative days or $150 \mathrm{mg}$ three times a week [130]. Recent data would suggest there is a risk of subtherapeutic rifabutin levels and daily RFB $150 \mathrm{mg}$ od may be used, but with close monitoring for RFB toxicity [77].

Co-prescribing integrase inhibitors and $R$ leads to induction of the UGT $1 \mathrm{~A} 1$ pathway and $\mathrm{P}$ - glycoprotein transporter leading to sub-therapeutic doses of integrase inhibitors at standard doses. Increasing the dose of the integrase inhibitor by a factor of $x$ 2 overcomes this with little-associated drug side effects [131]. Raltegravir dose is amended from $400 \mathrm{mg}$ twice daily to $800 \mathrm{mg}$ twice daily. Dolutegravir dose in increased from $50 \mathrm{mg}$ once daily to $50 \mathrm{mg}$ twice daily.

In the presence of integrase inhibitor resistance, the recommended dose of dolutegravir is also $50 \mathrm{mg}$ twice daily. Given this, those patients with documented integrase inhibitor resistance currently prescribed Dolutegravir at a higher dose may need to modify their ART if the anti-TB treatment that includes $R$ is necessary [132]. Of the novel anti-tuberculous drugs bedaquiline is metabolised by CYP 3A4 to an active metabolite. No dose adjustments are required when prescribed with nevirapine, but dose reduction and increase are seen with Efavirenz and lopinavir/ritonavir, respectively $(117,118)$. Delamanid shows minimal dose alteration, although some data is suggesting increased drug levels when prescribed with lopinavir/ritonavir, leading to increased risk of QT prolongation $(119,120)$.

\section{Key messages}

In the context of TB/HIV co-infection, the interaction with rifamycins and HIV therapy is the most challenging.

If prescribing an NNRTI, efavirenz is preferred combined with $R$. If a $\mathrm{PI}$ is prescribed, RFB is the rifamycin of choice.

Integrase inhibitors can be used in conjunction with $R$ at an increased dose.

\section{TB immune reconstitution inflammatory syndrome} Immune reconstitution inflammatory syndrome (IRIS) is an abhorrent immune response that occurs to MTB antigens in those patients in which there is immune recovery. The pathogenesis of IRIS remains unclear [135].

IRIS is commonly associated with those patients with HIV who have recently started ART.

\section{Definition and clinical symptoms}

These are the following features that define IRIS [11]:

- initial improvement on TB treatment followed by;

- worsening radiological features of TB; 
- new lymphadenopathy;

- neurological deterioration without any other cause;

- worsening clinical features of TB (cough, weight loss and fevers);

- new infective processes and poor compliance with medication and adverse drug events must all be excluded.

This phenomenon may occur at any time after initiation of TB treatment or HIV treatment, as well as be associated with an increase in $\mathrm{CD} 4+$ cell count. It is important to note that a positive AFB does not exclude the diagnosis of IRIS.

IRIS can be divided into clinical presentation, ranging from mild to severe. The majority of cases of IRIS are in the mild to moderate range and do not require hospital admission. Lymphadenopathy is the most common presenting feature. Other features include persistent low-grade fever and worsening symptoms of TB, despite adequate treatment. Mortality is rarely attributed to IRIS.

\section{Diagnosis}

There are no serological, radiological or definitive clinical markers to determine whether a patient has developed IRIS or not. IRIS is a diagnosis of exclusion [11].

\section{Pathogenesis}

In HIV infection, lack of CD4+ cells, as well as the presence of pathogens exerting an influence on local surrounding, by increasing IL-10 and IL-4 through mediated T cells, lead to immunosuppression. When ART is introduced, there is an increased ability to mount a response to TB. Thus, a shift in cytokine profiling from the more subtle and humoral TH2/Treg axis to the pro-inflammatory TH1 response, which interacts with mycobacterial antigens causing an inflammatory response, is observed [133]. This awakening of the immune response has also been seen in the case of TST, with patients who develop IRIS being more likely to convert from a negative to a positive result than those who do not develop IRIS [134].

Pre-ART high disease burden and monocyte counts have also been associated with higher probability of developing IRIS $[135,136]$. This may explain why patients develop IRIS when the difference in time between initiating TB treatment and ART is short (< 4 weeks) $[137,138]$.

This could also point towards future treatments being aimed at monocytes and monocyte-derived cytokines as potential targets for control of TB-IRIS [135].

\section{Treatment}

Lymphadenopathy is the most common presentation with TBIRIS [11]. The majority of patients will not need any significant intervention and the symptoms usually would settle while carrying on both ART and TB medications. Surgical intervention may be required in some cases, such as persistent pleural effusion and ascites.

High-dose systemic steroids have been shown to reduce hospital stay, improve chest radiography findings and the quality of life scoring [139]. There are no recognised alternative therapies, though there is a case series identifying montelukast as a potential treatment for IRIS [140].

One contentious issue that is present is the delay in initiating ART treatment in those patients with TB and HIV. There is a known association between developing IRIS and early initiation of ART treatment in relation to starting anti-TB treatment. The risk of developing IRIS increases with lower CD4+ cell counts at diagnosis. Initiating ART treatment during treatment of TB has been shown to decrease mortality rates, particularly in those with low CD4+ cell counts $(<50$ cells $/ \mu \mathrm{L}))[86-88,141]$.

\section{HIV-TB recurrence: relapse and reinfection}

Recurrence of TB disease mainly occurs within the first year of completing treatment. Recurrence can be subcategorized into reinfection (with a secondary Mycobacterium tuberculosis pathogen that may or may not be the same strain pattern as the first infection) and relapse (continuation of the same infection despite completion of treatment) [149]. Literature reviews find the following factors that independently increase the risk of recurrence:

- HIV infection;

- residual cavitation;

- greater area of involved lung tissue;

- positive sputum culture at 2 months of treatment;

- low socioeconomic status.

In their review of 32 studies, Panjabi et al. report higher recurrence rates in non-HIV patients at 6 months compared to 12 months following completion of treatment [55]. The rates of recurrence are higher in countries with high TB incidence. In studies involving HIV patients, recurrence rates were greater in individuals who were HIV+. In HIV+ individuals, predictors for TB recurrence include low $\mathrm{CD} 4+$ cell counts and less than 37 weeks of TB treatment [55].

Chaisson et al. report similar findings in their review of two studies, comparing the rates of recurrence of TB in HIV positive and negative individuals [142]. In India, Narayanan et al. report higher rates of recurrence in HIV+ individuals (14\% vs. 9\%), with nearly $88 \%$ due to reinfection with a different strain of MTB [143]. Glynn et al. found similar findings in South Africa, with recurrence rates of 24.4 per 100 person years in HIV positive compared to 4.7 per 100 in HIV-individuals [144]. As recurrence rates were measured 2 years following completion of treatment, the authors assumed that recurrence occurred due to reinfection. This is based on previous literature that states that nearly all recurrence takes place within the first 2 years following completion of treatment. Nevertheless, the findings highlight that HIV infection does increase the risk of MTB reinfection, with low CD4+ cell counts increasing that risk significantly [142]. However, the evidence suggests that HIV infection is not associated with relapse, but is an attributable risk factor for 
reinfection [145]. Relapse rates have been shown to decrease with directly observed therapy (DOT) [147].

In England and Wales, both new and recurrent episodes of TB disease are reported to the Health protection agency. Crofts et al. reviewed these reports from 1998-2005, and defined recurrence as an episode of TB disease occurring within 12 months following completion of treatment. They found that the recurrence rates in England and Wales are low (4.1 episodes per 1000 person-years of follow-up), but the risk is higher in HIV infection (7.6 episodes per 1000 person-years of follow-up) [148].

\section{Expert commentary and conclusions}

TB and HIV co-infections continue to be major public health concerns worldwide. Their deadly association have slowed down the TB incidence decline over the last two decades, representing a significant barrier towards TB elimination. At the same time, TB is still responsible for almost one-third of deaths among HIV-infected people.

Still many challenges lay ahead before being able to address this co-epidemic efficiently. Such problems cover all areas of TB control, such as diagnosis, drugs (availability of new and cheap drugs), treatment resistance, treatment regimens for both drugsensitive and drug-resistant TB, etc. In fact, the current battle against TB is based on several tools and "armamentaria", some of which are more than a century old. Regarding HIV, underdiagnosis, delayed diagnosis, retention in care, lack of full availability of ARVs and cost of second- and third-line drugs are among the key challenges.

Specifically, the clinical and public health management of HIVinfected individuals with MDR-TB is complicated to organise; middle and low-income countries are facing difficulties, especially those where a rampant epidemic of MDR/XDR-TB is ongoing.
However, not all is doom and gloom, during the last few years TB and HIV diagnosis and management have seen significant and unexpected improvements. On the HIV side, expansion of ART coverage, development of new updated guidelines aiming at universal treatment of those infected and the increasing availability of newer, more efficacious and less toxic ARVs are essential elements impacting on the two epidemics. On the TB side, diagnosis of MDR-TB is steadily becoming easier and faster, thanks to the new technologies based on PCR, new anti-TB drugs working with both sensitive and resistant strains (i.e. bedaquiline and delamanid) have been developed, and a few more are coming in the near future, new regimens (cheaper, shorter and/or more effective) have been introduced (such as the "Bangladesh regimen") or are being tested for MDR-TB and drug-sensitive-TB.

Nevertheless, this persisting TB/HIV co-epidemic, the cursed duet of this paper, needs to be faced with an integrated approach. One such approach is the one that could include the implementation of the $12 \mathrm{~TB} / \mathrm{HIV}$ collaborative activities recommended by WHO [1]. Such actions are recommended to systematically screen individuals infected with Mycobacterium tuberculosis, as well as those affected by TB in HIV/AIDS clinics; from the TB side, systematic screening for HIV infection is recommended in all TB cases. If fully operative in all countries, it could allow for every TB-HIV co-infected individual to be managed as per WHO guidelines ensuring, amongst other interventions, rapid initiation of effective ART.

Acknowledgements: none.

Funding statements: none.

Disclosure of interest: the authors declare that they have no competing interest.

\section{References}

[1] Global tuberculosis report 2016. WHO library cataloguing-in-publication data ISBN 978924 1565394

[2] Corbett EL, Watt CJ, Walker N, Maher D, Williams BG, Raviglione MC, et al. The growing burden of tuberculosis: global trends and interactions with the HIV epidemic. Arch Intern Med 2003;163:1009-21.

[3] Pietersen E, Ignatius E, Streicher EM, Mastrapa B, Padanilam X, Pooran A, et al. Longterm outcomes of patients with extensively drug-resistant tuberculosis in South Africa: a cohort study. Lancet 2014;383(9924):1230-9.

[4] O'Donnell MR, Daftary A, Frick M, HirschMoverman Y, Amico KR, Senthilingam M, et al. Re-inventing adherence: toward a patient-centered model of care for drug-resistant tuberculosis and HIV. Int J Tuberc Lung Dis 2016;20(4):430-4.

[5] Heysell SK, Ogarkov OB, Zhdanova S, Zorkaltseva E, Shugaeva S, Gratz J, et al. Undertreated HIV and drug-resistant tuberculosis at a referral hospital in Irkutsk, Siberia. Int J Tuberc Lung Dis 2016;20(2):187-92. http:// dx.doi.org/10.5588/ijtld.14.0961.

[6] World health organization. Antituberculosis drug resistance in the world. Fourth global report. WHO/HTM/TB/2008.394.

[7] Heysell SK, Moll AP, Gandhi NR, Eksteen F), Babaria P, Coovadia Y, et al. Extensively drug- resistant Mycobacterium tuberculosis from aspirates. Rural South Africa. Emerg Infect Dis 2010;16(3):557-60.

[8] Panel on antiretroviral guidelines for adults and adolescents. Guidelines for the use of antiretroviral agents in HIV-1-infected adults and adolescents. Department of Health and Human Services. Available at http://aidsinfo. nih.gov/contentfiles/Ivguidelines/AdultandAdolescentGL.pdf. Section accessed.[15th September 2016].

[10] Selwyn PA, Hartel D, Lewis VA, Schoenbaum $\mathrm{EE}$, Vermund $\mathrm{SH}$, Klein RS, et al. A prospective study of the risk of tuberculosis among intravenous drug users with human 
immunodeficiency virus infection. N Engl Med 1989;320:545-50.

[11] Pozniak AL, Coyne KM, Miller RF, Lipman $M C l$, Freedman AR, Ormerod LP, et al. British HIV association guidelines for the treatment of TB/HIV coinfection 2011. HIV Med 2011;12:517-24

[12] NICE guidelines for Tuberculosis 2016. NG33. Accessed [16th September 2016].

[13] Centers for disease control and prevention guidelines for using interferon gamma release assays to detect Mycobocterium tuberculosis infection, United States 2010.

[14] American thoracic society, CDC. Targeted tuberculin testing and treatment of latent tuberculosis infection. Am J Respir Crit Care Med 2000;161(4 Pt 2):S221-47.

[15] Centers for disease control and prevention: fatal and severe liver injuries associated with rifampin and pyrazinamide for latent tuberculosis infection, and revisions in American Thoracic Society/CDC Recommendations, United States, 2001.

[16] World health organization. Consolidated guidelines on the use of antiretroviral drugs for treating and preventing HIV infection: recommendations of a public health approach. WHO http://apps. who.int/iris/bitstream/10665/208825/1/

9789241549684_eng.pdf?ua=1 (2016).

[17] European centre for disease prevention and control guidelines on management of MDR and XDR tuberculosis 2011.

[18] Lee Y-M, Park K-H, Kim S-M, Park S, Lee S-O, Choi S-H, et al. Risk factors for false-negative results of T-SPOT. TB and tuberculin skin test in extra pulmonary tuberculosis. Infection 2013;41(6):1089-95.

[19] Health protection agency: interferon gamma release assays (IGRA) testing for Tuberculosis. Draft Interim HPA Guidance. HPA Tuberculosis Programme Board Internal HPA guidance July 2012.

[20] Menzies D, Pai M, Comstock G. Meta-analysis: new tests for the diagnosis of latent tuberculosis infection: areas of uncertainty and recommendations for research. Ann Intern Med 2007;146(5):340-54.

[21] Diel R, Goletti D, Ferrara G, Bothamley G, Cirillo D, Kampmann B, et al. Interferon gamma release assays for the diagnosis of latent Mycobacterium tuberculosis infection: a systematic review and meta-analysis. Eur Respir J 2011;37(1):88-99. http://dx.doi. org/10.1183/09031936.00115110 [Epub 2010 Oct 28]

[22] Ayubi E, Doosti-Irani A, Sanjari Moghaddam A, Sani M, Nazarzadeh M, Mostafavi E. The clinical usefulness of tuberculin skin test versus interferon gamma release assays for diagnosis of latent tuberculosis in HIV patients: a meta-analysis. Plos One 2016;11 (9):e0161983. http://dx.doi.org/10.1371/ journal.pone.0161983 [eCollection 2016].
[23] Balcells ME, Pérez CM, Chanqueo L, Lasso M, Villanueva $M$, Espinoza $M$, et al. A comparative study of two different methods for the detection of latent tuberculosis in HIV positive individuals in Chile. Int J Infect Dis 2008;12 (6):645-52. http://dx.doi.org/10.1016/j. ijid.2008.03.005 [Epub 2008 Jun 4].

[24] Kwan CK, Ernst JD. HIV and tuberculosis: a deadly human syndemic. Clin Microbiol Rev 2011;24(2):351-76. http://dx.doi.org/ 10.1128/CMR.00042-10.

[25] Bassett IV, Wang B, Chetty S, Giddy J, Losina E, Mazibuko M, et al. Intensive tuberculosis screening for HIV-infected patients starting antiretroviral therapy in Durban, South Africa. Clin Infect Dis 2010;51(7):823-9.

[26] Lawn SD, Wood R. Tuberculosis in antiretroviral treatment services in Resource- limited settings: addressing the challenges of screening and diagnosis. J Infect Dis 2011;204(Suppl. 4):S1159-67.

[27] Getahun H, Kittikraisak W, Heilig CM, Corbett EL, Ayles H, Cain KP, et al. Development of a standardized screening rule for tuberculosis in people living with HIV in resource-constrained settings: individual participant data metaanalysis of observational studies. Plos Med 2011;8(1):e1000391.

[28] Lawn SD, Myer L, Edwards D, Bekker LG, Wood R. Short-term and long-term risk of tuberculosis associated with CD4 cell recovery during antiretroviral therapy in South Africa. AIDS 2009:23:1717-25.

[29] Lawn SD, Brooks SV, Kranzer K, Nicol MP, Whitelaw A, et al. Screening for HIV-associated tuberculosis and rifampicin resistance before antiretroviral therapy using the Xpert MTB/RIF assay: a prospective study. Plos Med 2011;8(7):e1001067.

[30] Alvarez-Uria G, Azcona JM, Midde M, Naik PK, Reddy S, Reddy R. Rapid diagnosis of pulmonary and extrapulmonary tuberculosis in HIV-infected patients. Comparison of LED fluorescent microscopy and the Genexpert MTB/RIF assay in a district hospital in India; tuberculosis research and treatment; 2012.

[31] Lawn SD, Edwards D, Kranzer K, Vogt M, Bekker L, Wood R. Urine Lipoarabinomannan assay for tuberculosis screening before antiretroviral therapy diagnostic yield and association with immune reconstitution disease. AIDS 2009:23:1875-80.

[32] Hassim S, Shaw PA, Sangweni P, Malan L, Ntshani E, Mathibedi MJ, et al. Detection of a substantial rate of multidrug-resistant tuberculosis in an HIV-infected population in South Africa by active monitoring of sputum samples. Clin Infect Dis 2010;50(7):1053-9.

[33] Capocci S, Smith C, Morris S, Bhagani S, Cropley I, Abubakar I, et al. Decreasing cost effectiveness of testing for latent TB in HIV in a low TB incidence area. Eur Respir J 2015;46 (1):165-74. http://dx.doi.org/10.1183/ $\underline{09031936.00067114 .}$
[34] Cain KP, McCarthy KD, Heilig CM, Monkongdee P, Tasaneeyapan T, Kanara N, et al. An algorithm for tuberculosis screening and diagnosis in people with HIV. N Engl J Med 2010;362(8):707-16.

[35] Ticona E, Huaman MA, Huaroto LM, Burgos $M$, Brett $M$, Escombe $R$, et al. Tuberculosis screening using ability to provide sputum in an endemic emergency department. Eur Respir J 2016;47(1):330-3. http://dx.doi.org/ 10.1183/13993003.00877-2015.

[36] Kerkhoff AD, Kranzer $K$, Samandari T, Nakiyingi-Miiro J, Whalen $\mathrm{CC}$, Harries AD, et al. Systematic review of TST responses in people living with HIV in under-resourced settings: implications for isoniazid preventive therapy. Plos One 2012;7:e49928.

[37] Hoff ST, Peter JG, Theron G, Pascoe M, Tingskov PN, Aggerbeck $\mathrm{H}$, et al. Sensitivity of C-Tb: a novel RD-1-specific skin test for the diagnosis of tuberculosis infection. Eur Respir J 2016;47(3):919-28. $\quad$ http://dx.doi.org/ 10.1183/13993003.01464-2015.

[38] Rangaka MX, Diwakar L, Seldon R, van Cutsem G, Meintjes GA, Morroni C, et al. Clinical, immunological, and epidemiological importance of T cell responses in HIV-infected Africans. Clin Infect Dis 2007:44:1639-46.

[39] Cattamanchi A, Smith R, Steingart KR, Metcalfe JZ, Date A, Coleman C, et al. Interferongamma release assays for the diagnosis of latent tuberculosis infection in HIV-infected individuals: a systematic review and metaanalysis. J Acquir Immune Defic Syndr 2011; 56(3):230-8.

[40] Edwards TL, Valverde E, Mulder C, Cox C, Poling A. Pouched rats as detectors of tuberculosis: comparison to concentrated smear microscopy. Eur Respir J 2016;48(2):579-82. http://dx.doi.org/10.1183/ 13993003.00264-2016.

[41] Monkongdee P, McCarthy KD, Cain KP, Tasaneeyapan T, Nguyen HD, Nguyen TN, et al. Yield of acid-fast smear and mycobacterial culture for tuberculosis diagnosis in people with human immunodeficiency virus. Am J Respir Crit Care Med 2009;180(9):903-8.

[42] Getahun H, Harrington M, O'Brien R, Nunn P. Diagnosis of smear-negative pulmonary tuberculosis in people with HIV infection or AIDS in resource-constrained settings: informing urgent policy changes. Lancet 2007;369:2042-9.

[43] Kennedy DJ, Lewis WP, Barnes PF. Yield of bronchoscopy for the diagnosis of tuberculosis inpatients with human immunodeficiency virus infection. Chest 1992;102:1040-4.

[44] Mtei L, Matee M, Herfort O, Bakari M, Horsburgh CR, Waddell R, et al. High rates of clinical and subclinical tuberculosis among HIV-infected ambulatory subjects in Tanzania. Clin Infect Dis 2005;40(10):1500-7.

[45] Conde MB, Soares SL, Mello FC, Rezende VM, Almeida LL, Reingold AL, et al. Comparison of sputum induction with fiberoptic 
bronchoscopy in the diagnosis of tuberculosis: experience at an acquired immune deficiency syndrome reference center in Rio de Janeiro, Brazil. Am J Respir Crit Care Med 2000;162:2238.

[46] Riantawan P, Chaowalit P, Wongsangiem M, Rojanaraweewong P. Diagnostic value of pleural fluid adenosine deaminase in tuberculous pleuritis with reference to HIV coinfection and a Bayesian analysis. Chest 1999;116 (1):97-103.

[47] Baba K, Hoosen AA, Langeland N, DyrholRiise AM. Adenosine deaminase activity is a sensitive marker for the diagnosis of tuberculous pleuritis in patients with very low CD4 counts. Plos One 2008;3(7) [Article ID e2788].

[48] Luzze $H$, Elliott AM, Joloba ML, Odida $M$, Oweka-Onyee J, Nakiyingi J, et al. Evaluation of suspected tuberculous pleurisy: clinical and diagnostic findings in HIV-1-positive and HIVnegative adults in Uganda. Int J Tuberc Lung Dis 2001;5:746.

[49] Jones BE, Young SM, Antoniskis D, Davidson PT, Kramer F, Barnes PF, et al. Relationship of the manifestations of tuberculosis to CD4 cell counts in patients with human immunodeficiency virus infection. Am Rev Respir Dis 1993; 148:1292.

[50] Munseri PJ, Talbot EA, Bakari M, Matee $M$, Teixeira JP, von Reyn CF, et al. The bacteraemia of disseminated tuberculosis among HIV-infected patients with prolonged fever in Tanzania. Scand J Infect Dis 2011;43:696.

[51] Shafer RW, Kim DS, Weiss JP, Quale JM. Extrapulmonary tuberculosis in patients with human immunodeficiency virus infection. Medicine (Baltimore) 1991;70:384.

[52] Burynski N, Buynevich I, Loginov R, Goponyako S, Demidova E. Clinical and morphological features of HIV-associated tuberculosis. Eur Respir J 2015;46(Suppl. 59):PA2755. http://dx.doi.org/10.1183/ 13993003.congress-2015.PA2755

[53] World health organization. Policy update: automated real-time nucleic acid amplification technology for rapid and simultaneous detection of tuberculosis and rifampicin resistance: Xpert MTB/RIF system for the diagnosis of pulmonary and extrapulmonary $\mathrm{TB}$ in adults and children. http://www.stoptb. org/wg/gli/assets/documents/WHO\% 20Policy\%20Statement $\% 200 n \% 20$ Xpert $\%$ 20MTB-RIF\%202013\%20pre\%20publication \%2022102013.pdf (2013)

[54] Mfinanga SG, Kirenga BJ, Chanda DM, Mutayoba B, Mthiyane T, Yimer G, et al. Early versus delayed initiation of highly active antiretroviral therapy for HIV-positive adults with newly diagnosed pulmonary tuberculosis (TB-HAART): a prospective, international, randomised, placebo-controlled trial. Lancet Infect Dis 2014;14:563-71.

[55] Panjabi R, Comstock GW, GolubJE. Recurrent tuberculosis and its risk factors: adequately treated patients are still at high risk. Int J Tubercul Lung Dis 2007;11(8):828-37.

[56] Albert H, Nathavitharana RR, Isaacs C, Pai M, Denkinger CM, Boehme CC. Development, roll-out and impact of Xpert MTB/RIF for tuberculosis: what lessons have we learnt and how can we do better? Eur Respir J 2016;48(2):516-25. http://dx.doi.org/ 10.1183/13993003.00543-2016.

[57] Steingart KR, Schiller I, Horne DJ, Pai M, Boehme CC, Dendukuri N. Xpert(R) MTB/RIF assay for pulmonary tuberculosis and rifampicin resistance in adults. Cochrane Database Syst Rev 2014;1:CD009593 [Epub 2014/01/ 23. doi: 10.1002/14651858.CD009593.pub3. PubMed PMID: 24448973; PubMed Central PMCID: PMCPMC4470349].

[58] Walusimbi S, Bwanga F, De Costa A, Haile M1, Joloba M, Hoffner S. Meta-analysis to compare the accuracy of GeneXpert, MODS and the WHO 2007 algorithm for diagnosis of smear-negative pulmonary tuberculosis. BMC Infect Dis 2013;13:507. http://dx.doi.org/ 10.1186/1471-2334-13-507

[59] Theron G, Pinto L, Peter J, Mishra HK, Mishra $H K$, van Zyl-Smit R, et al. The use of an automated quantitative polymerase chain reaction (Xpert MTB/RIF) to predict the sputum smear status of tuberculosis patients. Clin Infect Dis 2012:54:384.

[60] Boyles TH, Hughes J, Cox V, Burton R, Meintjes G, Mendelson M, et al. False-positive Xpert ${ }^{\circledR}$ MTB/RIF assays in previously treated patients: need for caution in interpreting results. Int J Tuberc Lung Dis 2014;18:876.

[61] Boehme CC, Nabeta P, Hillemann D, Nicol MP, Shenai S, Krapp F, et al. Rapid molecular detection of tuberculosis and rifampin resistance. N Engl J Med 2010;363(11):1005-15.

[62] Lawn SD, Kerkhoff AD, Nicol MP, Meintjes G. Underestimation of the true specificity of the urine lipoarabinomannan point-of-care diagnostic assay for HIV-associated tuberculosis. J Acquir Immune Defic Syndr 2015;69:e144.

[63] Shah M, Hanrahan C, Wang ZY, Dendukuri N, Lawn SD, Denkinger CM, et al. Lateral flow urine lipoarabinomannan assay for detecting active tuberculosis in HIV-positive adults. Cochrane Database Syst Rev 2016:CD011420.

[64] Minion J, Leung E, Talbot E, Dheda K, Pai M, Menzies D. Diagnosing tuberculosis with urine lipoarabinomannan: systematic review and meta-analysis. Eur Respir J 2011;38 (6):1398-405.

[65] Lawn SD, Kerkhoff AD, Vogt M, Wood R. Diagnostic accuracy of a low-cost, urine antigen, point-of-care screening assay for HIVassociated pulmonary tuberculosis before antiretroviral therapy: a descriptive study. Lancet Infect Dis 2012;12(3):201-9.

[66] Peter JG, Zijenah LS, Chanda D, Clowes P, Lesosky M, Gina P, et al. Effect on mortality of point-of-care, urine-based lipoarabinomannan testing to guide tuberculosis treatment initiation in HIV-positive hospital inpatients: a pragmatic, parallel-group, multicountry, open-label, randomised controlled trial. Lancet 2016:387:1187.

[67] Hassim S, Shaw PA, Sangweni P, Malan L, Ntshani E, Mathibedi MJ, et al. Detection of a substantial rate of multidrug-resistant tuberculosis in an HIV-infected population in South Africa by active monitoring of sputum samples. Clin Infect Dis 2010;50:1053.

[68] GolubJE, Durovni B, King BS, Cavalacante SC, Pacheco AG, Moulton LH, et al. Recurrent tuberculosis in HIV-infected patients in Rio de Janeiro, Brazil. AIDS 2008;22:2527-33.

[69] Suthar AB, Lawn SD, del Amo J, Getahun $H$, Dye C, Sculier D, et al. Antiretroviral therapy for prevention of tuberculosis in adults with HIV: a systematic review and meta-analysis. Plos Med 2012;9:e1001270.

[70] Danel C, Moh R, Gabillard D, Badje A, Le Carrou J, et al. A trial of early antiretrovirals and isoniazid preventive therapy in Africa. N Engl J Med 2015;373:808-22.

[71] Samandari T, Agizew TB, Nyirenda S, Tedla $Z$, Sibanda $T$, shang $N$, et al. 6-month versus 36-month isoniazid preventive treatment for tuberculosis in adults with HIV infection in Botswana: a randomised, double-blind, placebo-controlled trial. Lancet 2011;377:158898.

[72] Getahun H, Matteelli A, Abubakar I, Hauer B, Pontali E, Migliori GB. Advancing global programmatic management of latent tuberculosis infection for at risk populations. Eur Respir J 2016;47(5):1327-30. http://dx.doi. огя/10.1183/13993003.00449-2016.

[73] Kaplan JE, Benson C, Holmes KK, Brooks JT, Pau A, Masur H. Centers for disease control and prevention (CDC); National institutes of health; HIV medicine association of the infectious diseases society of America. Guidelines for prevention and treatment of opportunistic infections in HIV-infected adults and adolescents: recommendations from CDC, the National institutes of health, and the HIV medicine association of the infectious diseases society of America MMWR Recomm Rep 2009;58(RR-4):1-207 [quiz CE1-4].

[74] WHO policy on collaborative TB/HIV activities: guidelines for national programmes and other stakeholders [Internet]. 2012. Available from: http://whqlibdoc.who.int/publications/ 2012/9789241503006_eng_Annexes.pdf.

[75] WHO. Protocol 4. Management of tuberculosis and HIV co-infection: clinical protocol for the WHO European Region - 2013 Revision [Internet]. 2013. Available from: http://www.euro. who.int/en/health-topics/communicablediseases/tuberculosis/publications/2013/ 2013-revision-protocol-4.-management-oftuberculosis-and-hiv-coinfection.

[76] CDC. Managing drug interactions in the treatment of HIV-related tuberculosis [Internet]. 2013. Available from: http://www.cdc.gov/ tb/TB_HIV_Drugs/default.htm. 
[77] TB Care I. International standards for tuberculosis care. 3rd ed. The Hague; 2014.

[78] Nahid P, Dorman SE, Alipanah N, Barry PM, Brozek JL, Cattamanchi A, et al. Official american thoracic society/Centers for disease control and prevention/Infectious diseases society of American clinical practice guidelines: treatment of drug-susceptible tuberculosis. Clin Infect Dis 2016;63(7):e147-95.

[79] Meintjes G. Management of drug-resistant TB in patients with HIV co-infection. J Int AIDS Soc 2014;17(4 Suppl. 3):19508. http://dx.doi. org/10.7448/IAS.17.4.19508 [eCollection 2014].

[80] Phillips PPJ, Fielding K, Nunn AJ. An evaluation of culture results during treatment for tuberculosis as surrogate endpoints for treatment failure and relapse. Plos One 2013;8(5): e63840.

[81] Aber VR, Nunn AJ. Short term chemotherapy of tuberculosis. Factors affecting relapse following short-term chemotherapy [in French]. Bull Int Union Tuberc 1978;53(4):276-80.

[82] Lawn SD, Harries AD, Meintjes G, Getahun H, Havlir DV, Wood R. Reducing deaths from tuberculosis in antiretroviral treatment programmes in sub-Saharan Africa. AIDS 2012;26:2121-33.

[83] Havlir DV, Kendall MA, Ive P, Kumwenda J, Swindells S, Qasba SS, et al. Timing of antiretroviral therapy for HIV-1 infection and tuberculosis. N Engl J Med 2011;365:1482-91.

[84] Blanc FX, Sok T, Laureillard D, Borand L, Rekacewicz C, Nerrienet E, et al. Earlier versus later start of antiretroviral therapy in HIV-infected adults with tuberculosis. N Engl J Med 2011;365:1471-81.

[85] Abdool Karim SS, Naidoo K, Grobler A, Padayatchi N, Baxter C, Gray AL, et al. Integration of antiretroviral therapy with tuberculosis treatment. $N$ Engl J Med 2011;365:1492-501

[86] Manosuthi W, Mankatitham W, Lueangniyomkul A, Thongyen S, Likanonsakul S, Suwanvattana $P$, et al. Time to initiate antiretroviral therapy between 4 weeks and 12 weeks of tuberculosis treatment in HIVinfected patients: results from the TIME study. J Acquir Immune Defic Syndr 2012;60:377-83.

[87] Uthman OA, Okwundu C, Gbenga K, Volmink J, Dowdy D, Zumla A, et al. Optimal timing of antiretroviral therapy initiation for HIVinfected adults with newly diagnosed pulmonary tuberculosis: a systematic review and meta-analysis. Ann Intern Med 2015;163:32-9.

[88] Yan S, Chen L, Wu W, Fu Z, Zhang H, Li Z, et al. Early versus delayed antiretroviral therapy for HIV and tuberculosis co-infected patients: a systematic review and meta-analysis of randomized controlled trials. Plos One 2015;10:e0127645.

[89] Torok ME, Yen NT, Chau TT, Mai NT, Phu NH, Mai PP, et al. Timing of initiation of antiretroviral therapy in human immunodeficiency virus (HIV) - associated tuberculous meningitis. Clin Infect Dis 2011;52:1374-83.

[90] Schutz C, Meintjes G, Almajid F, Wilkinson RJ, Pozniak A. Clinical management of tuberculosis and HIV-1 co-infection. Eur Respir J 2010;36(6):1460-81

[92] Padayatchi N, Naidu N, Yende-Zuma N, O'Donnell MR, Naidoo K, Augustine S, et al. Implementation and operational research: clinical impact of the Xpert MTB/ RIF assay in patients with multidrug-resistant tuberculosis. J Acquir Immune Defic Syndr 2016;73(1):e1-7 [Epub 2016/08/11. doi: 10.1097/qai.0000000000001110. PubMed PMID: 27509173].

[93] WHO treatment guidelines for drug-resistant tuberculosis 2016 update. Geneva: World Health Organization; 2016. ISBN-13: 978-924-154963-9

[94] Moodley R, Godec TR. Short-course treatment for multidrug-resistant tuberculosis: the STREAM trials. Eur Respir Rev 2016;25 (139):29-35. http://dx.doi.org/10.1183/ 16000617.0080-2015.

[95] Sotgiu G, Tiberi S, D'Ambrosio L, Centis R, Alffenaar JW, Caminero JA, et al. Faster for less: the new "shorter" regimen for multidrug-resistant tuberculosis. Eur Respir J 2016 [Epub 2016/09/03. doi: 10.1183/ 13993003.01249-2016. PubMed PMID: 27587544].

[96] Carroll MW, Lee M, Cai Y, Hallahan CW, Shaw PA, Min JH, et al. Frequency of adverse reactions to first- and second-line anti-tuberculosis chemotherapy in a Korean cohort. Int J Tuberc Lung Dis 2012;16(7):961-6 [Epub 2012/05/16. doi: 10.5588/ijtld.11.0574. PubMed PMID: 22584241].

[97] Daskapan A, de Lange WC, Akkerman OW, Kosterink JG, van der Werf TS, Stienstra Y, et al. The role of therapeutic drug monitoring in individualised drug dosage and exposure measurement in tuberculosis and HIV coinfection. Eur Respir J 2015;45(2):569-71. http://dx.doi.org/10.1183/ 09031936.00142614

[98] Zuur MA, Akkerman OW, Touw DJ, van der Werf TS, Cobelens F, Burger DM, et al. Dried blood spots can help decrease the burden on patients dually infected with multidrug-resistant tuberculosis and HIV. Eur Respir J 2016;48 (3):932-4. http://dx.doi.org/10.1183/ 13993003.00599-2016.

[99] Ghimire S, Bolhuis MS, Sturkenboom MG, Akkerman OW, de Lange WC, van der Werf TS, et al. Incorporating therapeutic drug monitoring into the World Health Organization hierarchy of tuberculosis diagnostics. Eur Resріг J 2016;47(6):1867-9. http://dx.doi.org/ 10.1183/13993003.00040-2016.

[100] van der Burgt EP, Sturkenboom MG, Bolhuis MS, Akkerman OW, Kosterink JG, de Lange WC, et al. End TB with precision treatment! Eur Respir J 2016;47(2):680-2. http://dx.doi. огя/10.1183/13993003.01285-2015.
[101] Zuur MA, Akkerman OW, Davies Forsman L, Hu Y, Zheng R, Bruchfeld J, et al. Fixed-dose combination and therapeutic drug monitoring in tuberculosis: friend or foe? Eur Respir J 2016;48(4):1230-3. $\quad$ http://dx.doi.org/ 10.1183/13993003.00833-2016.

[102] Sturkenboom MG, Akkerman OW, van Altena R, de Lange WC, KosterinkJG, van der Werf TS, et al. Dosage of isoniazid and rifampicin poorly predicts drug exposure in tuberculosis patients. Eur Respir J 2016;48(4):1237-9. http://dx.doi.org/10.1183/ 13993003.00986-2016.

[103] Campos PE, Suarez PG, SanchezJ, Zavala D, Arevalo J, Ticona E, et al. Multidrug-resistant Mycobacterium tuberculosis in HIV-infected persons, Peru. Emerg Infect Dis 2003;9 (12):1571-8 [Epub 2004/01/15. doi: 10.3201/eid0912.020731. PubMed PMID: 14720398; PubMed Central PMCID: PMCPMC3034326].

[104] Kenyon TA, Mwasekaga MJ, Huebner R, Rumisha D, Binkin N, Maganu E. Low levels of drug resistance amidst rapidly increasing tuberculosis and human immunodeficiency virus co-epidemics in Botswana. Int J Tuberc Lung Dis 1999;3(1):4-11 [Epub 1999/03/27. PubMed PMID: 10094163].

[105] Mesfin YM, Hailemariam D, Biadglign S, Kibret KT. Association between HIV/AIDS and multi-drug resistance tuberculosis: a systematic review and meta-analysis. Plos One 2014;9(1):e82235. http://dx.doi.org/ 10.1371/journal.pone.0082235 [PubMed PMID: PMC3885391].

[106] Heysell SK, Ogarkov OB, Zhdanova S, Zorkaltseva E, Shugaeva S, Gratz J, et al. Undertreated HIV and drug-resistant tuberculosis at a referral hospital in Irkutsk, Siberia. Int J Tuberc Lung Dis 2016;20(2):187-92 [Epub 2016/01/23. doi: 10.5588/ijtld.14.0961. PubMed PMID: 26792470; PubMed Central PMCID: PMCPMC4863947].

[107] Umanah T, Ncayiyana J, Padanilam X, Nyasulu PS. Treatment outcomes in multidrug resistant tuberculosis-human immunodeficiency virus co-infected patients on anti-retroviral therapy at Sizwe Tropical disease hospital Johannesburg, South Africa. BMC Infect Dis 2015;15:478 [Epub 2015/10/30. doi: 10.1186/s12879-015-1214-3. PubMed PMID: 26511616; PubMed Central PMCID: PMCPMC4625623]

[108] Uthman OA, Okwundu C, Gbenga K, Volmink J, Dowdy D, Zumla A, et al. Optimal timing of antiretroviral therapy initiation for HIVinfected adults with newly diagnosed pulmonary tuberculosis: a systematic review and meta-analysis. Ann Intern Med 2015;163(1):32-9 [Epub 2015/07/07. doi: 10.7326/m14-2979. PubMed PMID: 26148280].

[109] Naidoo K, Baxter C, Abdool Karim SS. When to start antiretroviral therapy during tuberculosis treatment? Curr Opin Infect Dis 2013;26 
(1):35-42 [Epub 2012/11/29. doi: 10.1097/ QCO.0b013e32835ba8f9. PubMed PMID: 23188213; PubMed Central PMCID: PMCPMC3616247].

[110] Manosuthi W, Chottanapand S, Thongyen S, Chaovavanich A, Sungkanuparph S. Survival rate and risk factors of mortality among HIV/ tuberculosis-coinfected patients with and without antiretroviral therapy. J Acquir Immune Defic Syndr 2006;43(1):42-6 [Epub 2006/08/04. doi: 10.1097/01.qai.0000230521.86964.86. PubMed PMID: 16885778].

[111] Odone A, Amadasi S, White RG, cohen T, Grant AD, Houben RM. The impact of antiretroviral therapy on mortality in HIV positive people during tuberculosis treatment: a systematic review and meta-analysis. Plos One 2014;9(11):e112017 [Epub 2014/11/13. doi: 10.1371/journal.pone.0112017. PubMed PMID: 25391135; PubMed Central PMCID: PMCPMC4229142].

[112] Arentz M, Pavlinac P, Kimerling ME, Horne DJ, Falzon D, Schunemann $\mathrm{HJ}$, et al. Use of anti-retroviral therapy in tuberculosis patients on second-line anti-TB regimens: a systematic review. Plos One 2012;7(11):e47370 [Epub 2012/11/13. doi: 10.1371/journal. pone.0047370. PubMed PMID: 23144818; PubMed Central PMCID: PMCPMC3489892].

[113] Lin YJ, Liao CM. Quantifying the impact of drug combination regimens on TB treatment efficacy and multidrug resistance probability. J Antimicrob Chemother 2015;70(12):3273-82 [Epub 2015/08/28. doi: 10.1093/jac/ dkv247. PubMed PMID: 26311836]

[114] O'Donnell MR, Wolf A, Werner L, Horsburgh $C R$, Padayatchi $N$. Adherence in the treatment of patients with extensively drug-resistant tuberculosis and HIV in South Africa: a prospective cohort study. J Acquir Immune Defic Syndr 2014;67(1):22-9 [Epub 2014/05/30. doi: 10.1097/qai.0000000000000221. PubMed PMID: 24872138; PubMed Central PMCID: PMCPMC4410008].

[115] Ndjeka N, Conradie F, Schnippel K, Hughes J, Bantubani $\mathrm{N}$, Ferreira $\mathrm{H}$, et al. Treatment of drug-resistant tuberculosis with bedaquiline in a high HIV prevalence setting: an interim cohort analysis. Int J Tuberc Lung Dis 2015;19 (8):979-85 [Epub 2015/07/15. doi: 10.5588/ ijtld.14.0944. PubMed PMID: 26162365].

[116] Svensson EM, Aweeka F, Park JG, Marzan F, Dooley KE, Karlsson MO. Model-based estimates of the effects of efavirenz on bedaquiline pharmacokinetics and suggested dose adjustments for patients coinfected with HIV and tuberculosis. Antimicrob Agents Chemother 2013;57(6):2780-7 [Epub 2013/04/ 11. doi: 10.1128/aac.00191-13. PubMed PMID: 23571542; PubMed Central PMCID: PMCPMC3716161].

[117]Svensson EM, Dooley KE, Karlsson MO. Impact of lopinavir-ritonavir or nevirapine on bedaquiline exposures and potential implications for patients with tuberculosis-HIV coinfection. Antimicrob Agents Chemother 2014;58(11):6406-12 [Epub 2014/08/13. doi: 10.1128/aac.03246-14. PubMed PMID: 25114140; PubMed Central PMCID: PMCPMC4249405].

[118] Mallikaarjun S, Wells C, Petersen C, Paccaly A, Shoaf SE, Patil S, et al. Delamanid coadministered with antiretroviral drugs or antituberculosis drugs shows no clinically relevant drug-drug interactions in healthy subjects. Antimicrob Agents Chemother 2016;60(10):5976-85 [Epub 2016/07/28. doi: 10.1128/aac.00509-16. PubMed PMID: 27458223]

[119] Lewis JM, Sloan DJ. The role of delamanid in the treatment of drug-resistant tuberculosis. Ther Clin Risk Manag 2015;11:779-91. http:// dx.doi.org/10.2147/TCRM. 571076 $\overline{\text { eCollec- }}$ tion 2015].

[120] Clinical Trials Gov NCT02333799. https://clinicaltrials.gov accessed 23rd October 2016.

[121] Siwendu S, Mitchell M, Diacon AH, von Groote-Bidlingmaier F. Recruitment challenges for clinical trials with novel regimens for drug-resistant tuberculosis. Eur Respir J 2016;47(2):670-2. http://dx.doi.org/ 10.1183/13993003.01330-2015.

[122] Conradie F, Diacon A, Mendel C, Everitt D, Van Niekerk C, Howell P, et al. Interim results of nix-TB clinical study of pretomanid, bedaquiline and linezolid for treatment of XDR and treatment intolerant/failed MDR TB. OA-3117 presented at the 47th Union World Conference on Lung Health. Liverpool, UK: 26 October -29 October 2016.

[123] Alffenaar JW, Akkerman OW, Anthony R, Tiberi S, Heysell S, Grobusch MP, et al. Individualizing management of extensively drug-resistant tuberculosis: diagnostics, treatment, and biomarkers. Expert Rev Anti Infect Ther 2016.

[124] Baciewicz AM, Chrisman CR, Finch CK, Self TH. Update on rifampin and rifabutin drug interactions. Am J Med Sci 2008;335:126-36.

[125] Wenning LA, Hanley WD, Brainard DM, Petry AS, Ghosh $\mathrm{K}$, Jin B, et al. Effect of rifampin, a potent inducer of drug-metabolizing enzymes, on the pharmacokinetics of raltegravir. Antimicrob Agents Chemother 2009;53:2852-6.

[126] Greiner B, Eichelbaum M, Fritz P, Kreichgauer HP, von Richter $\mathrm{O}$, Zundler $\mathrm{J}$, et al. The role of intestinal P-glycoprotein in the interaction of digoxin and rifampin. I Clin Invest 1999; 104:147-53

[127] Boulle A, Van Cutsem G, Cohen K, Hilderbrand K, Mathee S, Abrahams M, et al. Outcomes of nevirapine- and efavirenz based antiretroviral therapy when coadministered with rifampicin-based antitubercular therapy. JAMA 2008;300:530-9.

[128] Manosuthi W, Kiertiburanakul S, Sungkanuparph S, Ruxrungtham K, Vibhagool A, Rattanasiri S, et al. Efavirenz $600 \mathrm{mg} /$ day versus efavirenz $800 \mathrm{mg} /$ day in HIV infected patients with tuberculosis receiving rifampicin: 48 weeks results. AIDS 2006;20:131-2.

[129] Mcllleron H, Meintjes G, Burman WJ, Maartens $G$. Complications of antiretroviral therapy in patients with tuberculosis: drug interactions, toxicity, and immune reconstitution inflammatory syndrome. J Infect Dis 2007;196(Suppl. 1):S63-75.

[130] Centers for disease control and prevention. Updated guidelines for the use of rifamycins for the treatment of tuberculosis among HIVinfected patients taking protease inhibitors or non-nucleoside reverse transcriptase inhibitors. MMWR Recomm Rep 2004;53(15):1112.

[131] Mena A, Vázquez P, Castro Á, López S, Bello L, Pedreira JD. Clinical experience of raltegravir-containing regimens in HIV-infected patients during rifampicin-containing treatment of tuberculosis. J Antimicrob Chemother 2011; 66:951-2.

[132] Regazzi M, Carvalho AC, Villani P, Matteelli A. Treatment optimization in patients coinfected with HIV and Mycobacterium tuberculosis infections: focus on drug-drug interactions with rifamycins. Clin Pharmacokinet 2014;53(6):489-507. http://dx.doi.org/ 10.1007/s40262-014-0144-3.

[133] Sun HY, Singh N. Immune reconstitution inflammatory syndrome in non-HIV immunocompromised patients. Curr Opin Infect Dis 2009;22.

[134] Narita M, Ashkin D, Hollender ES, Pitchenik AE. Paradoxical worsening of tuberculosis following antiretroviral therapy in patients with AIDS. Am J Respir Crit Care Med 1998;158:157-61.

[135] Ravimohan S, Tamuhla N, Nfanyana K, Steenhoff AP, Lethogile R, Frank I, et al. Robust reconstitution of tuberculosis-specific polyfunctional CD4+ T-cell responses and rising systemic interleukin 6 in paradoxical tuberculosis-associated immune reconstitution inflammatory syndrome. Clin Infect Dis 2016;62(6):795-803 [doi: 10.1093/cid/ civ978. Epub 2015 Nov 26].

[136] Ravimohan S, Tamuhla N, Steenhoff AP, Lethogile R, Nfanyana K, Bellamy SL, et al. Immunological profiling of tuberculosis-associated immune reconstitution inflammatory syndrome and non-immune reconstitution inflammatory syndrome death in HIV-infected adults with pulmonary tuberculosis starting antiretroviral therapy: a prospective observational cohort study. Lancet Infect Dis 2015;15:429-38.

[137] Luetkemeyer AF, Kendall MA, Nyirenda M, Wu X, Ive $P$, Benson CA, et al. Tuberculosis immune reconstitution inflammatory syndrome in A5221 STRIDE: timing, severity and implications for HIV-TB programs. J Acquired Immune Def Syndr 1999 2014;65 (4): 423

[138] Abay SM, Deribe K, Reda AA, Biadgilign S, Datiko D, Assefa T, et al. The effect of early 
initiation of antiretroviral therapy in TB/HIVcoinfected patients: a systematic review and meta-analysis. J Int Assoc Prov AIDS Care 2015;14(6):560-70.

[139] Lanzafame $M$, Sandro V. Tuberculosisimmune reconstitution inflammatory syndrome. I Clin Tubercul Mycobact Dis 2016;3:6-9.

[140] Hardwick C, White D, Morris E, Monteiro EF Breen RA, Lipman M. Montelukast in the treatment of HIV associated immune reconstitution disease. Sex Transm Infect 2006;82 (6):513-4

[141] Abdool Karim SS, Naidoo K, Grobler A, Padayatchi N, Baxter C, Gray A, et al. Timing of initiation of antiretroviral drugs during tuberculosis therapy. $N$ Engl J Med 2010;362:697-706.

[142] Chaisson R, Churchyard G. Recurrent tuberculosis-relapse, re-infection and HIV. J Infect Dis 2010;201(5):653-5.

[143] Narayanan S, Swaminathan S, Supply P, Shanmugam S, Narendran G, Hari L, et al. Impact of HIV infection on the recurrence of tuberculosis in South India. I Infect Dis 2010;201(5):691-703 [doi:10.1086/650528].
[144]Glynn JR, Murray J, Bester A, Nelson G, Shearer S, Sonnenberg P. High rates of recurrence in HIV-infected and HIV-uninfected patients with tuberculosis. I Infect Dis 2010;201(5):704-11 [doi: 10.1086/650529].

[145] Lambert ML, Epco H, Van Deun A, Roberfroid D, Boelaert M, Van der Stuyft P. Recurrence in tuberculosis: relapse or reinfection. Lancet Infect Dis 2003:3:282-7.

[147] Weis S, Slocum P, Blais F, King B, Nunn M, Burgis $M$, et al. The effect of directly observed therapy on the rates of drug resistance and relapse of tuberculosis. N Engl J Med 1994;330:1179-84.

[148]Zumla A, Malon P, Henderson J, Grange J. Impact of HIV infection on tuberculosis. Postgrad Med J BMJ ) 2000;76:259-68.

[149] Guerra-Assunção JA, Houben RMG), Crampin AC, Mzembe T, Mallard K, Coll F, et al. Recurrence due to relapse or reinfection with mycobacterium tuberculosis: a whole-genome sequencing approach in a large, population-based cohort with a high HIV infection prevalence and active follow-up. J Infect Dis 2015;211(7):1154-63. http://dx.doi.org/ 10.1093 /infdis/jiu574.
[150] van der Werf MJ, Hollo V, Ködmön C, Dara M, Catchpole M. Eligibility for shorter treatment of multidrug-resistant tuberculosis in the European Union. Eur Respir J 2016 [in press]

[151] Javaid A, Ahmad N, Shaheen Z, Hayat Khan A. Applicability of World Health Organization's recommended new shorter regimen in an MDR-TB high burden country. Eur Respir J 2016 [in press].

[152] Lönnroth K, Migliori GB, Abubakar I, D'Ambrosio L, de Vries G, Diel R, et al. Towards tuberculosis elimination: an action framework for low-incidence countries. ERJ Express 2015. http://dx.doi.org/10.1183/ 09031936.00214014.

[153] Getahun H, Matteelli A, Abubakar I, Aziz MA, Baddeley A, Barreira D, et al. Management of latent Mycobocterium tuberculosis infection: WHO guidelines for low tuberculosis burden countries. Eur Respir | 2015;46:1563-76. http://dx.doi.org/10.1183/ 